\title{
RESEARCH
}

Open Access

\section{ITPR3 facilitates tumor growth, metastasis and stemness by inducing the NF-KB/CD44 pathway in urinary bladder carcinoma}

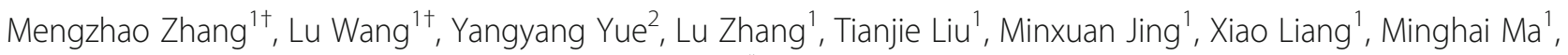
Shan $\mathrm{Xu}^{1}$, Ke Wang ${ }^{1}$, Xinyang Wang ${ }^{1}$ and Jinhai Fan ${ }^{1,3^{*}}$

\begin{abstract}
Background: Bladder carcinoma is one of the most common urological cancers. ITPR3, as a ubiquitous endoplasmic reticulum calcium channel protein, was reported to be involved in the development and progression of various types of cancer. However, the potential roles and molecular mechanism of ITPR3 in bladder cancer are still unclear. Herein, we elucidated a novel role of ITPR3 in regulating the proliferation, metastasis, and stemness of bladder cancer cells.

Methods: The expression of ITPR3 in bladder cancer was analyzed using public databases and bladder cancer tissue microarrays. To demonstrate the role of ITPR3 in regulating the NF-KB/CD44 pathway and the progression of bladder cancer, a series of molecular biology and biochemistry methods was performed on clinical tissues, along with in vivo and in vitro experiments. The methods used included western blot assay, quantitative RT-PCR assay, immunofluorescence assay, immunohistochemistry (IHC) assays, wound healing assay, Transwell assay, colony formation assay, tumorsphere formation assay, cell flow cytometry analysis, EdU assay, MTT assay, cell transfection, bisulfite sequencing PCR (BSP), a xenograft tumor model and a tail vein cancer metastasis model.

Results: Higher ITPR3 expression was found in bladder cancer tissues and bladder cancer cells compared with the corresponding normal peritumor tissues and SV-HUC-1 cells, which was attributed to demethylation in the ITPR3 promoter region. ITPR3 promoted the proliferation of bladder cancer by accelerating cell cycle transformation and promoted local invasion and distant metastasis by inducing epithelial-to-mesenchymal transition (EMT). Meanwhile, ITPR3 maintained the cancer stemness phenotype by regulating CD44 expression. NF-kB, which is upstream of CD44, also played a critical role in this process.
\end{abstract}

Conclusions: Our study clarifies that ITPR3 serves as an oncogene in bladder cancer cells and represents a novel candidate for bladder cancer diagnosis and treatment.

Keywords: ITPR3, Proliferation, Metastasis, Cancer stem cell, Bladder cancer, Epithelial-mesenchymal transition

\footnotetext{
*Correspondence: jinhaif029@126.com

${ }^{\dagger}$ Mengzhao Zhang and Lu Wang contributed equally to this work.

'Department of Urology, The First Affiliated Hospital of Xi'an Jiaotong

University, \#277 Yanta West Road, Xi'an 710061, China

${ }^{3}$ Oncology Research Lab, Key Laboratory of Environment and Genes Related

to Diseases, Ministry of education, Xi'an, China

Full list of author information is available at the end of the article
}

C C The Author(s). 2021 Open Access This article is licensed under a Creative Commons Attribution 4.0 International License, which permits use, sharing, adaptation, distribution and reproduction in any medium or format, as long as you give appropriate credit to the original author(s) and the source, provide a link to the Creative Commons licence, and indicate if changes were made. The images or other third party material in this article are included in the article's Creative Commons licence, unless indicated otherwise in a credit line to the material. If material is not included in the article's Creative Commons licence and your intended use is not permitted by statutory regulation or exceeds the permitted use, you will need to obtain permission directly from the copyright holder. To view a copy of this licence, visit http://creativecommons.org/licenses/by/4.0/ The Creative Commons Public Domain Dedication waiver (http://creativecommons.org/publicdomain/zero/1.0/) applies to the data made available in this article, unless otherwise stated in a credit line to the data. 


\section{Background}

Bladder cancer (BCa) is one of the most common urological malignancies in developing countries and the second most common urological malignancy in developed countries, with an estimated 900,000 new cases and 250,000 deaths due to bladder cancer worldwide each year [1]. Most bladder cancers are transitional cell carcinomas, with more than $70 \%$ of new patients having non-muscle-invasive $\mathrm{BCa}$ (stage $\mathrm{Tis}, \mathrm{Ta}, \mathrm{T} 1$ ) and less than $30 \%$ having muscle-invasive $\mathrm{BCa}$ (stage T2, T3, T4). Approximately $10-30 \%$ of non-muscle-invasive $\mathrm{BCa}$ will eventually progress to muscle-invasive $\mathrm{BCa}$, and even metastatic bladder cancer patients and $50 \%$ of newly diagnosed bladder cancer patients will experience disease relapse, thus leading to distant metastasis and poor prognoses [2,3]. As is well-known, bladder cancer characterized by high recurrence and distant metastasis is usually accompanied by a poor prognosis [4]. Therefore, there is an urgent need to understand the biological and molecular mechanisms underlying $\mathrm{BCa}$ malignant proliferation and distant metastasis.

ITPR3, which is also known as Type 3 inositol 1,4,5trisphosphate receptor, is one of three highly homologous isoforms of ITPRs (inositol 1,4,5 trisphosphate receptors) (ITPR1, ITPR2 and ITPR3), which are ubiquitous $\mathrm{Ca}^{2+}$ channels located at mitochondria/endoplasmic reticulum (ER) contact sites that mediate $\mathrm{Ca}{ }^{2+}$ release from the ER to mitochondria [5]. Intracellular $\mathrm{Ca}^{2+}$, which acts as a second messenger, can regulate gene transcription, cell proliferation, migration, invasion, and cell death. Targeting specific calcium signaling has become an emerging research area for human cancer therapy [6]. ITPRs, as the most extensive $\mathrm{Ca}^{2+}$ channels, are receiving increasing attention, among which ITPR3 is the principal isoform [7]. It has been reported that ITPRs are emerging as critical sites for the regulation of cell death and survival processes, dysregulation of which leads to oncogenesis. ITPR3, as the principal isoform of ITPRs, was considered to have an anticancer effect by promoting proapoptotic mitochondrial $\mathrm{Ca} 2+$ transfer [8]. However, three recent studies have found that cancer cells can adapt to the upregulation of ITPR3 and depend on it, thus driving oncogenesis and malignant cell transformation $[6,7,9]$. Until now, the effect of ITPR3 in human cancer has remained controversial and confusing. However, as a calcium channel regulatory protein between the ER and mitochondria, the biological effects and expression of ITPR3 in human cancer development and progression are still unclear, especially in BCa.

In this study, we demonstrated for the first time that ITPR3 is abnormally overexpressed in bladder cancer tissues compared with normal tissues. In addition, we found that ITPR3 accelerated the malignant progression of bladder cancer by promoting proliferation, metastasis, and cancer stemness in vitro and in vivo, and in this process, the role of the NF- $\mathrm{kB} / \mathrm{CD} 44$ signaling pathway could not be neglected. The revelations of the molecular mechanism and function of ITPR3 will be helpful in understanding the malignant progression of bladder cancer, in which ITPR3 might be a novel target for the diagnosis and treatment of bladder cancer, especially metastatic bladder cancer, in the future.

\section{Materials and methods \\ Cell culture}

The human BCa cell lines T24, UM-UC-3, 5637, and $253 \mathrm{~J}$ and the normal urothelium cell line SV-HUC-1, which is an SV-40 immortalized human uroepithelial cell line, were purchased from the American Type Culture Collection (ATCC, Manassas, VA, USA). The cell lines mentioned above (except for 5637) were maintained in DMEM culture medium, and 5637 cells were cultured in RPMI-1640 medium supplemented with 10\% FBS (Gibco, Grand Island, NY, USA) and 1\% antibioticantimycotic (HyClone Laboratories, Logan, UT) at $37{ }^{\circ} \mathrm{C}$ aired with $5 \% \mathrm{CO}_{2}$ and $95 \%$ humidity in a cell incubator. The T24-L subcellular line containing luciferase was generated as described in previous research [10] and cultured in DMEM under the same conditions described above. All cell lines used in the research were at early passages.

\section{Chemicals and reagents}

MTT purchased from Sigma-Aldrich Co. (St. Louis, MO, USA) was dissolved in $5 \mathrm{mg} / \mathrm{ml}$ with PBS (phosphate-buffered normal saline). Transwell chambers with $8 \mu \mathrm{M}$ pore polycarbonate membrane filters were purchased from Millipore (Darmstadt, Germany). TGF- $\beta$ $(10 \mathrm{ng} / \mathrm{ml})$, EGF $(20 \mathrm{ng} / \mathrm{ml})$, and bFGF $(10 \mathrm{ng} / \mathrm{ml})$ were purchased from PeproTech (New Jersey, USA). Tumor necrosis factor-alpha (TNF- $\alpha$, Invitrogen, Carlsbad, CA, USA), as an activator of the NF- $\mathrm{B}$ signaling pathway, was obtained from Invitrogen, and the final concentration was $10 \mathrm{ng} / \mathrm{ml}$ in culture medium maintained for 24 $\mathrm{h}$ in subsequent experiments. 5-Aza-2'-deoxycytidine used to induce demethylation in bladder cancer cells at a concentration of $2.5 \mu \mathrm{M}$ or $5 \mu \mathrm{M}$ for $72 \mathrm{~h}$ was purchased from TargetMol (Boston, USA).

\section{MTT assay}

Bladder cancer cells in the logarithmic growth phase were treated with the indicated treatment, and then the viability of the bladder cancer cells was detected by a 3(4,5-dimethylthiazol-2-yl)-2,5-diphenyltetrazolium bromide (MTT) (Sigma, St. Louis, MO, USA) assay. The specific procedure was as follows. Bladder cancer cells were suspended at a concentration of 20,000 cells per milliliter and seeded into 96-well plates at $200 \mu \mathrm{l}$ per well. 
After incubation in the cell incubator for a specific time, $20 \mu \mathrm{l} \mathrm{MTT}$ was added to $180 \mu \mathrm{l}$ complete medium per well. Four hours later, the absorbance was measured at $490 \mathrm{~nm}$ by an ELISA reader (Bio-Rad, Hercules, CA, USA). The data are the result of three independent experiments.

\section{Bisulfite sequencing PCR (BSP)}

$\mathrm{CpG}$ islands are closely related to the methylation level of genes. CPG islands in the promoter region of ITPR3 were predicted by MethPrimer (http://www.urogene.org/ methprimer/). Genomic DNA $(1 \mu \mathrm{g})$ from bladder cancer cells and SV-HUC-1 cells was modified and purified with sodium bisulfite using the EpiTect Bisulfite Kit (Qiagen, cat: 59824. Hilden, Germany). Bisulfite genomic sequencing was used to analyze the methylated CpGs in the ITPR3 promoter, and the primers used for bisulfite sequencing PCR were ITPR3 F: 5'-ATTTGTATGT GTGTGGTGGTTT-3' (sense) and 5' -TAAAACCATT AACRAAACCCTC-3' (antisense). Amplified bisulfate PCR products were cloned into the pMD18-T simple vector (Takara, Dalian, China). Ten bacterial colonies containing 43 methylation sites were selected for sequencing at Sangon Biotech (Shanghai, China).

\section{Clinical specimens, tissue chip and immunohistochemistry} (IHC) assays

$\mathrm{BCa}$ patients' tissues and its corresponding normal tissues $(n=11)$ were obtained from the Department of Urology, The First Affiliated Hospital of Xi'an Jiaotong University, Xi'an, China. All clinical samples used in the research were approved by the Ethical Committee of the Hospital, and informed consent was obtained from all the BCa patients $(n=11)$ who participated in this study. In order to further investigate the expression of ITPR3 in $\mathrm{BCa}$ and matched normal tissues, we purchased a BCa tissue chip (Cat No. HBlaU060CS02) from Outdo Biotech Co., Ltd. (Shanghai, China) containing 30 individual $\mathrm{BCa}$ patient tissues, with each adjacent noncancerous tissue placed beside its matched cancer tissue. The tissue microarray slide was deparaffinized at $60^{\circ} \mathrm{C}$ for $4 \mathrm{~h}$, rehydrated in graded solutions of ethanol (100, 95, 80, 70 and 50\%) for $3 \mathrm{~min}$, and then subjected to antigen repair at $121^{\circ} \mathrm{C}$ for $5 \mathrm{~min}$ and endogenous enzyme blocking at room temperature for $60 \mathrm{~min}$. After blocking with 5\% BSA for $1 \mathrm{~h}$, the tissue chip was incubated with the primary antibody at $4{ }^{\circ} \mathrm{C}$ overnight. On the second day, after incubation with Envision-HRP secondary antibody for $30 \mathrm{~min}$ at room temperature, the images were detected by an Olympus BX51 microscope (Olympus Corporation, Tokyo, Japan) after staining with a DAB kit according to the manufacturer's protocols. The staining images were assessed according to the staining intensity $(0,1,2+, 3+)$ and the percentage of positive cells $(0(0 \%), 1$ (1-25\%), 2 (26-50\%), 3 (51$75 \%)$ and $4(76-100 \%))$. The degree of protein expression in the image was evaluated by the combination of the staining score and the percentage of positive cells and presented in the way of (0 score), weak (1-4 score), moderate (5-8 score) and strong (9-12 score).

\section{Plasmid transfection and lentiviral infection}

The lentiviral vector (Psi-LVRU6GP), which encodes short hairpin RNA (shRNA) targeting ITPR3 and scramble control shRNA, was constructed by GeneCopoeia (Guangzhou, China). The lentiviruses were packaged to improve the transfection efficiency according to the procedure described previously [11]. Lentivirus-overexpressing CD44 and empty lentivirus vectors were obtained from GeneChem Company (Shanghai, China). The cells were used for subsequent experiments after lentivirus transfection for $48 \mathrm{~h}$ with $8 \mu \mathrm{g} / \mathrm{ml}$ polybrene existed.

\section{Wound healing assay}

The wound healing assay was executed to assess the migration ability of 5637 and 253 J cells under specific conditions. The cells were seeded into 6-well plates with the marker lines across the bottom side and scratched with a $200 \mu \mathrm{l}$ pipette tip to mark the distance when the cell density reached almost $100 \%$. Serum-free medium was added to the 6 -well plates, and images were captured by an inverted microscope (Olympus, Tokyo, Japan) every $24 \mathrm{~h}$ until the scratch was almost closed. This experiment was repeated in triplicate.

\section{Transwell assay}

Migration and invasion assays were performed via Boyden chambers with an $8-\mu \mathrm{m}$ pore size (Millipore, Germany) to evaluate the migration and invasion abilities of bladder cancer cells under given conditions. For the migration assay, chambers plated into 24-well plates were seeded with $4 \times 10^{4} 5637$ and $2 \times 10^{4} 253 \mathrm{~J}$ cells suspended in $200 \mu \mathrm{l}$ serum-free culture medium in the upper chamber without Matrigel, and $800 \mu \mathrm{l}$ medium with $10 \%$ FBS was added to the lower chamber for $24 \mathrm{~h}$. For the invasion assay, $8 \times 10^{4} 5637$ and $4 \times 10^{4} 253 \mathrm{~J}$ suspended in $200 \mu \mathrm{l}$ serum-free culture medium were added to the upper chamber with $60 \mu \mathrm{l}$ Matrigel (Sigma, St. Louis, MO, USA) and incubated in a cell incubator at $37^{\circ} \mathrm{C}$ for $4 \mathrm{~h}$, and $800 \mu \mathrm{l}$ medium with $10 \%$ FBS was added to the lower chamber for $48 \mathrm{~h}$. After washing with PBS three times, fixing with $4 \%$ paraformaldehyde for $15 \mathrm{~min}$ and staining with $0.1 \%$ crystal violet for $5 \mathrm{~min}$, the visible cells were observed and counted under an inverted light microscope (magnification, $\times 100$ ) in three random fields for each chamber. The experiment was executed in triplicate. 


\section{Immunofluorescence assay}

Immunofluorescence assays were conducted as previously described [12]. Briefly, BCa cells were fixed with $4 \%$ paraformaldehyde, permeabilized with $0.5 \%$ Triton- 100 in PBS, blocked with 5\% BSA (bovine serum albumin) and incubated with the indicated primary antibodies dissolved in PBS 1:200 at $4{ }^{\circ} \mathrm{C}$ overnight. After incubation with the fluorescent secondary antibody at room temperature for 1 $\mathrm{h}$, staining with DAPI for $5 \mathrm{~min}$ in the dark and sealing with glycerin, the stained images were captured under a positive fluorescence microscope (Olympus, Tokyo, Japan). The experiments were performed at least in triplicate.

\section{Quantitative RT-PCR}

The total RNA was isolated from BCa cells with RNAfast 200 reagents (Feijie Biotechnology, Shanghai, China) according to the manufacturer's instructions, quantified by absorbance at $260 \mathrm{~nm}$ and reverse-transcribed to complementary DNA using a Prime Script RT-PCR kit (Takara Bio Dalian, China). The cDNA was amplified to detect the expression of specific genes using a CFX96 Real-Time PCR system (Bio-Rad, CA, USA) with SYBRGreen PCR Master Mix (Takara Bio, Dalian, China). Gene-specific primers were as follows: ITPR1, F: GCGGAGGGATCGACAAATGG and R: TGGGAC ATAGCTTAAAGAGGCA; ITPR2, F: CACCTTGGGG TTAGTGGATGA and R: CTCGGTGTGGTTCCCTTG T; ITPR3, F: CCAAGCAGACTAAGCAGGACA and R: ACACTGCCATACTTCACGACA; and 18S, F: CAGC CACCCGAGATTGAGCA and R: TAGTAGCGAC GGGCGGTGTG. Gene mRNA expression levels were assessed by the $2^{-\Delta \Delta \mathrm{Ct}}$ method. $18 \mathrm{~S}$ was used for normalization.

\section{Western blot assay}

After treatment with specific experimental conditions, the total proteins were isolated with RIPA lysis buffer (Catalog Number P0013B, Beyotime, China) with a protease inhibitor, phosphatase inhibitor and 0.1 M PMSF (Catalog Number ST506, Beyotime, China). Nuclear and cytoplasmic proteins were extracted using a Nuclear Extraction Kit (Abcam, ab113474, Shanghai, China). The collection of proteins and western blot assays were performed as previously described [12]. The following antibodies were used in the experiment: ITPR3 (BS72246) used for WB was purchased from Bioworld Technology. Inc., and ITPR3 (ab264282) used for IHC was purchased from Abcam. ITPR1 (19962-1-AP), E2F1 (12171-1-AP), Cyclin D1 (26939-1-AP), Cyclin B1 (55004-1-AP), CDK2 (10122-1-AP), P21 (10355-1-AP), MMP2 (10373-2-AP), MMP9 (10375-2-AP), CD44 (15675-1AP), P63 (12143-1-AP), OCT4 (11263-1-AP), IkB $\alpha$ (10268-1-AP), and KLF4 (11880-1-AP) were purchased from Proteintech Group. SOX2 (A0561) and $\beta$-actin (AC026) were purchased from Abclonal. ITPR2 (DF13336) was obtained from Affinity. E-cadherin (3195), N-cadherin (13116), Vimentin (5741), NF-kB

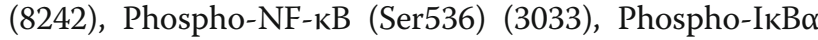
(Ser32) (2859), Snail1 (3879), and Snail 2 (9585) were purchased from CST (Cell Signaling Technology).

\section{Colony formation assay and tumorsphere formation assay} After treatment with various desired conditions, 5637 and $253 \mathrm{~J} \mathrm{BCa}$ cells were seeded into 6-well plates at 1000 cells per well and incubated in a cell incubator for seven days with the medium replaced every $48 \mathrm{~h}$. After washing with PBS three times, the cells were fixed with $4 \%$ paraformaldehyde for $15 \mathrm{~min}$ and stained with $0.1 \%$ crystal violet for $5 \mathrm{~min}$ to make the cells visible. The clonogenicity was assessed by counting the number of colonies in five random fields at 100X magnification. The experiments were conducted in triplicate. $\mathrm{BCa}$ cells were suspended and seeded into 6-well ultralow attachment plates with $3 \mathrm{ml} /$ well cancer stemness medium containing $2 \mathrm{xB}^{27}, 1 \mathrm{xN}_{2}$ supplement, $20 \mathrm{ng} / \mathrm{ml}$ EGF (epidermal growth factor) and $10 \mathrm{ng} / \mathrm{ml}$ bFGF (basic fibroblast growth factor). After cultivation for two weeks, tumorsphere formation was counted and analyzed by microscopy in five random fields. The experiment was executed in triplicate.

\section{Cell flow cytometry analysis}

Human BCa cell lines 253 J and 5637 were maintained in DMEM or RPMI-1640 medium supplemented with $10 \% \mathrm{FBS}$ in $6 \mathrm{~cm}$ dishes. After treatment with the given conditions, the cells were collected and suspended in PBS, fixed with $70 \%$ ice-cold ethanol at $4{ }^{\circ} \mathrm{C}$ overnight and then incubated with $50 \mu \mathrm{g} / \mathrm{ml} \mathrm{PI}$ (propidium iodide) and $100 \mu \mathrm{g} / \mathrm{ml}$ RNase A (1:1) in PBS at room temperature in the dark for at least $15 \mathrm{~min}$. Finally, a FACSCalibur $^{\text {Tix }}$ flow cytometer (BD Biosciences, Franklin Lakes, NJ, USA) was used to assess the staining signals of the $\mathrm{BCa}$ cells, and Cell Quest software version 3.3 (BD Biosciences) was used to analyze the percentage of cell cycles distributed according the manufacturer's instructions. The experiment was repeated three times.

\section{EdU assay}

The proliferation ability of $\mathrm{BCa}$ cells was detected by EdU assay using the EdU Cell Proliferation Kit with Alexa Fluor 594 (Beyotime, China). Cells were washed with PBS three times and incubated with complete medium with $10 \mu \mathrm{M}$ EdU in a cell incubator for at least $2 \mathrm{~h}$. Then, the cells were washed with PBS to remove the EdU probe and culture medium, fixed with $4 \%$ paraformaldehyde for $10 \mathrm{~min}$ at room temperature, and stained with DAPI for $5 \mathrm{~min}$ in the dark. The cells were 
observed under a positive fluorescence microscope (Olympus, Tokyo, Japan) at 100x magnification in five random fields. The staining signals were captured, analyzed, and shown as fold changes compared with the control. The experiment was repeated three times.

\section{Gene set enrichment analysis}

The mRNA expression data of $408 \mathrm{BCa}$ patients were downloaded from The Cancer Genome Atlas (TCGA) database (https://www.cancer.gov/tcga). The ITPR3 high-expression group (top 25\%, 102 of 408 patients in TCGA FPKM cohort) and ITPR3 low-expression group (top 25\%, 102 of 408 patients in TCGA FPKM cohort) were set up. Gene Set Enrichment Analysis (GSEA) 2.0 software was used to analyze the significantly changed pathways and top 100 altered genes of the two groups after the data were submitted to the software and the hallmark gene sets were selected for analysis (http:// software.broadinstitute.org/gsea/msigdb/collections. jsp\#H) [13].

\section{Xenograft tumor model and tail vein cancer metastasis model}

All male athymic nude mice used in the study were approved by the Ethical Committee of the First Affiliated Hospital of Medical College, Xi'an Jiaotong University, Xi'an, China. Ten 4-week-old nude mice were randomly separated into two groups with each group containing 5 mice and then injected subcutaneously in both flanks with $100 \mu \mathrm{l}$ serum-free culture medium containing $50 \mu \mathrm{l}$ Matrigel and $5 \times 10^{6} 5637$ cells (shCon or shITPR3) after 7 days of feeding. Then, the mouse weight and tumor size were recorded and measured every three days until the nude mice with tumors were euthanized to harvest the tumors at day 30. The tumors were weighed, measured, and then stained by immunohistochemistry. The formula for calculating the tumor volume was (length $x$ width $\left.{ }^{2}\right) \times 0.5$. The total protein of the tumors was extracted with RIPA lysis buffer and detected by a western blot assay. A nude mouse tail vein cancer metastasis model was established as previously described [12]. Briefly, ten 4-week-old nude mice were randomly divided into two groups with each group containing 5 mice, and $2 \times 10^{6}$ T24-L BCa cells (shCon or shITPR3) labeled with luciferase suspended in $200 \mu \mathrm{l}$ serum-free culture medium were injected via the tail vein with an insulin needle after 7 days of feeding. Bioluminescence imaging (BLI) was performed to monitor distant metastasis in the lung and other organs at day 30 after injection with $450 \mathrm{mg} / \mathrm{kg}$ D-luciferin (Abcam, ab143655, Shanghai, China). Lungs with distant metastatic foci were obtained from nude mice to observe the number of lung surface metastatic foci and then stained by hematoxylin-eosin (HE) and immunohistochemistry after the mice were euthanized.

\section{Bioinformatics and statistical analysis}

The GSE3167 dataset used to analyze the expression of ITPR3 between tumor and normal tissues and the GDS183 dataset used to detect the expression in different clinical stages were downloaded from NCBI GEO (Gene Expression Omnibus). The expression level of ITPR3 in bladder cancer and normal tissues and the overall survival and disease-free survival related to ITPR3 mRNA expression level were analyzed with GEPIA (http://gepia.cancer-pku.cn/) and cBioPortal (www.cbioportal.org) for The Cancer Genome Atlas (TCGA). ITPR3 mRNA expression in multiple kinds of cancers, including bladder cancer, was analyzed from the Oncomine database (https://www.oncomine.org/). Briefly, the differences between two groups were analyzed by Student's t-test implemented with GraphPad Prism 7.0 software (GraphPad, CA, USA). The data are presented as the mean \pm SD of three independent experiments. $P<0.05$ indicated statistical significance.

\section{Results \\ ITPR3 was commonly overexpressed in BCa cells and tissues}

To explore the expression pattern of ITPR3 in BCa tissues and cells, immunohistochemical staining was performed on a bladder cancer tissue microarray containing 30 cases of $\mathrm{BCa}$ and matched adjacent nontumor tissues. The results showed that ITPR3 was not only significantly upregulated in $\mathrm{BCa}$ tissues compared with corresponding normal peritumor tissues but also positively correlated with clinicopathological stages (Ta-T4) and tumor invasion degree (NMIBC and MIBC) (Fig. 1a, b). Then, we further examined ITPR3 expression in bladder cancer cell lines and SVHUC-1 cells (SV-40 immortalized uroepithelial cells) at both the protein and mRNA levels (Fig. 1c, d) and found that ITPR3 was significantly upregulated in BCa cell lines, especially in 5637 and $253 \mathrm{~J}$ cells, compared to SV-HUC-1 cells, which was consistent with the immunohistochemistry (IHC) results. ITPR3 was also upregulated in the $\mathrm{BCa}$ tissues compared with its matched normal adjacent tissues, as detected by the western blot assay (Fig. 1e). At the same time, bioinformatics analysis was also used to confirm our conclusion. From the analysis of GEO datasets (GSE3167, GDS183), the GEPIA website (based on the TCGA database) and the TCGA dataset, we found that ITPR3 was overexpressed in bladder cancer and positively correlated with clinical stages, which was also consistent with the result from immunohistochemistry (IHC) (Supplementary Fig. 1. A-C). The 


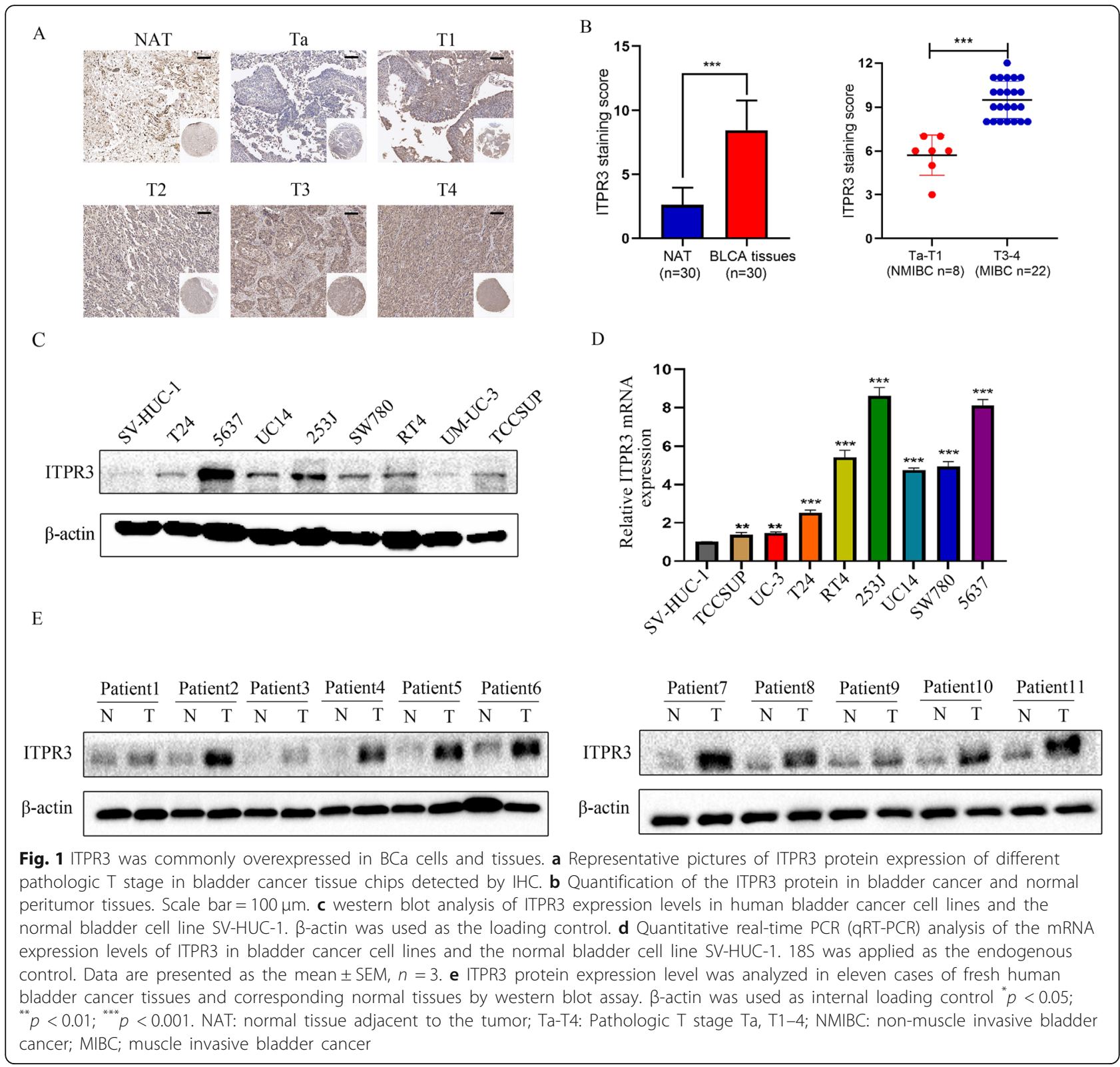

results from the analysis of the Oncomine dataset indicated that ITPR3 was widely overexpressed in various human tumors, including bladder cancer, kidney cancer, pancreatic cancer, etc. (Supplementary Fig. 1. D). From the results of Sanchez-Carbayo's research from the Oncomine website, we also reached the same conclusion that ITPR3 was highly expressed in bladder cancer (Supplementary Fig. 1. E). Although there is considerable evidence that ITPR3 is overexpressed in bladder cancer, we failed to observe a positive relationship between ITPR3 and the prognosis of patients with bladder cancer, including overall survival (OS) or disease-free survival (DFS) (Supplementary Fig. 1. F).

\section{Significant overexpression of ITPR3 in bladder cancer is} attributed to demethylation of its promoter

The methylation status of ITPR3 in SV-HUC-1, 5637 and $253 \mathrm{~J}$ cells was analyzed by bisulfite sequencing PCR (BSP) and the representative images were shown in Fig. 2a. The methylation level of ITPR3 in SVHUC-1 cells was much higher than that in bladder cancer cells 5637 and $253 \mathrm{~J}$. Meanwhile, we also found that there was a negative correlation between the methylation level of ITPR3 and its mRNA expression level (Fig. 2b). CpG islands in the promoter region of ITPR3 was predicted by MethPrimer 2.0 and there was four CpG island in the promoter including three $\mathrm{CpG}$ islands longer than 200 bp (Fig. 2c). Through UALCAN TOOL, we found ITPR3 


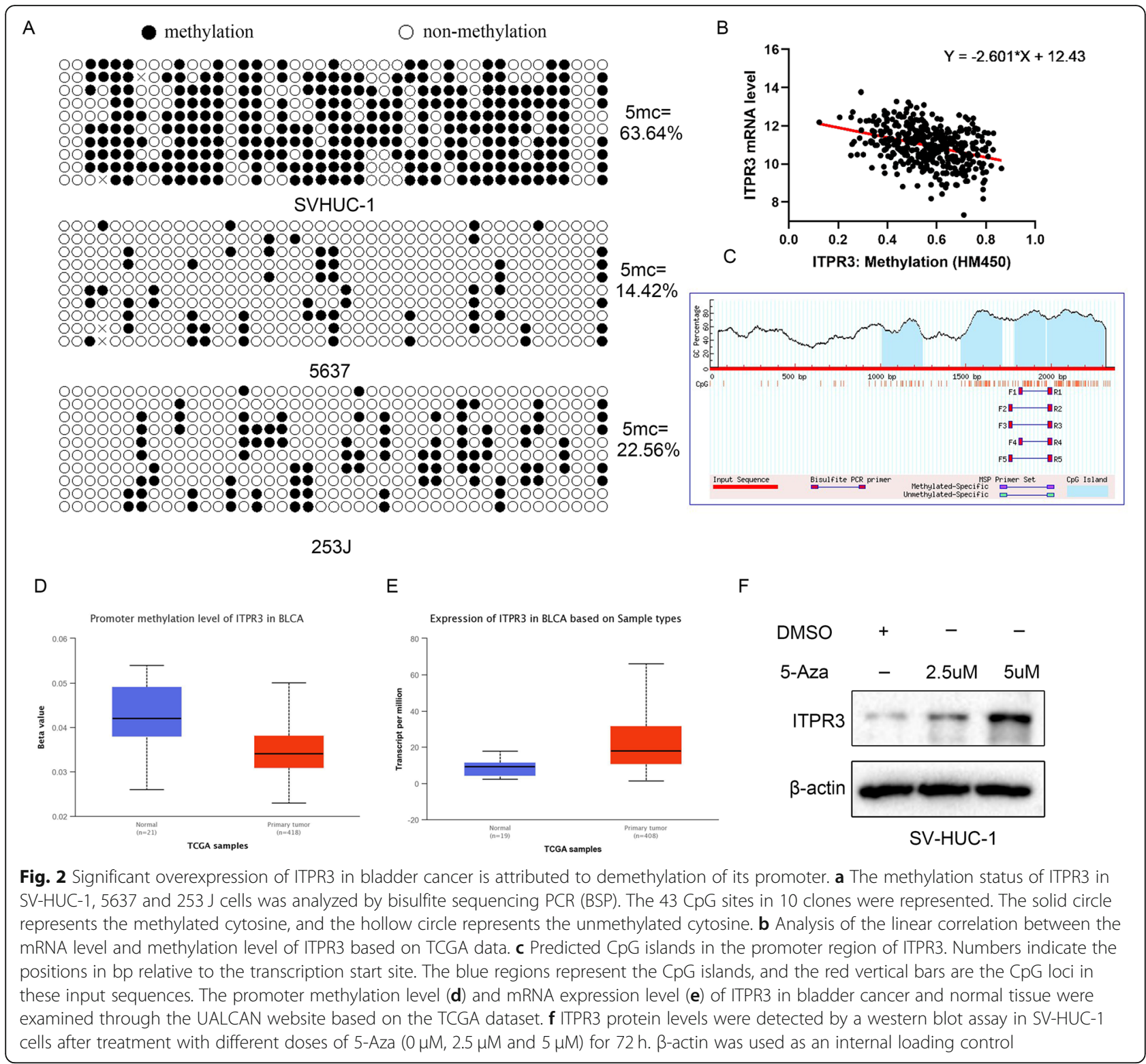

was in high expression in bladder cancer while the methylation level of ITPR3 was in low level (Fig. 2d, e). With the treatment of increasing dose of 5-Aza in the normal bladder cell line SVHUC-1, the protein level of ITPR3 was upregulation in a dose-dependent manner (Fig. 2f). The above results fully indicated that the high expression of ITPR3 was caused by demethylation of its promoter region.

ITPR3 inhibition decreases BCa cell proliferation in vitro The expression of ITPR3 was knocked down by shRNA in 5637 and $253 \mathrm{~J}$ cells with relatively high ITPR3 expression to investigate the function of ITPR3 in bladder cancer, and the inefficiency of knockdown was detected by a western blot assay (Fig. 3a). Stably transfected 5637 and $253 \mathrm{~J}$ shITPR3 cells were used for subsequent experiments. The MTT assay revealed that ITPR3 inhibition suppressed the proliferation ability of BCa cells (5637 and $253 \mathrm{~J}$ ) in a time-dependent manner (Fig. 3b). DNA replication activity, which is usually considered to represent the proliferation capacity, was detected by an EdU staining assay. As is shown in Fig. 2c, ITPR3 suppression significantly reduced the EdU staining signals in 5637 and $253 \mathrm{~J}$ cells (Fig. 3c). A similar result was also observed in flow cytometry analysis, in which cell cycle arrest in the G0/G1 phase was observed after ITPR3 knockdown (Fig. 3d). Meanwhile, the expression of cell cycle-related genes such as E2F1, Cyclin D1, Cyclin B1, and CDK2 was also decreased after ITPR3 knockdown while P21, as a classical tumor suppressor gene was 


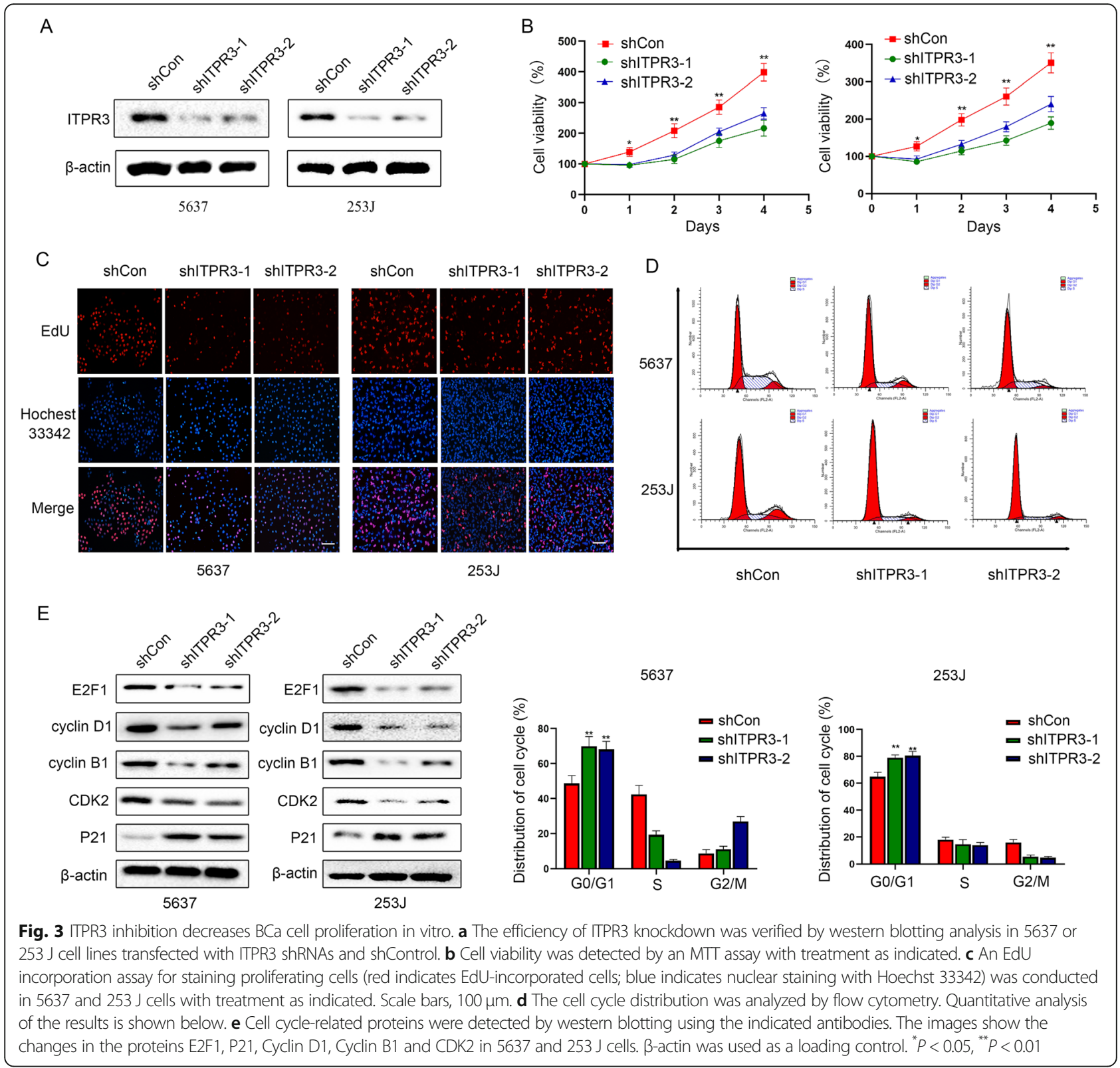

upregulated (Fig. 3e). All the data indicated that ITPR3 loss suppressed $\mathrm{BCa}$ cell proliferation capacity.

\section{ITPR3 loss inhibits the migration and invasiveness of}

\section{bladder cancer cells in vitro}

Sustained proliferation and a high invasion and metastasis capacity are the main manifestations of the malignant progression of tumors [14, 15]. We have demonstrated that ITPR3 can promote cell proliferation by accelerating cell cycle transformation. Furthermore, to investigate the potential role of ITPR3 in the migration and invasion capacity of bladder cancer cells, wound healing assays and transwell assays were conducted simultaneously after ITPR3 knockdown. The results obtained suggest that ITPR3 silencing inhibited the wound healing rate compared with that in the control 5637 and 253 J cells (Fig. 4a, b). Similar results were also observed in the migration assay. A Matrigel invasion assay was conducted to assess the distant metastatic capacity of bladder cancer cells, and ITPR3 inhibition also suppressed the invasion ability of BCa cells (Fig. 4c, d). Matrix metalloproteinases, which belong to a large family of proteases, have been demonstrated to play vital roles in tissue remodeling and cancer progression and metastasis, of which MMP2 and MMP9 are the most important [16, 17]. We found that the MMP2 and MMP9 protein levels as detected by western blot assay were suppressed in 5637 and 253 J cells after ITPR3 knockdown (Fig. 4e, f). 


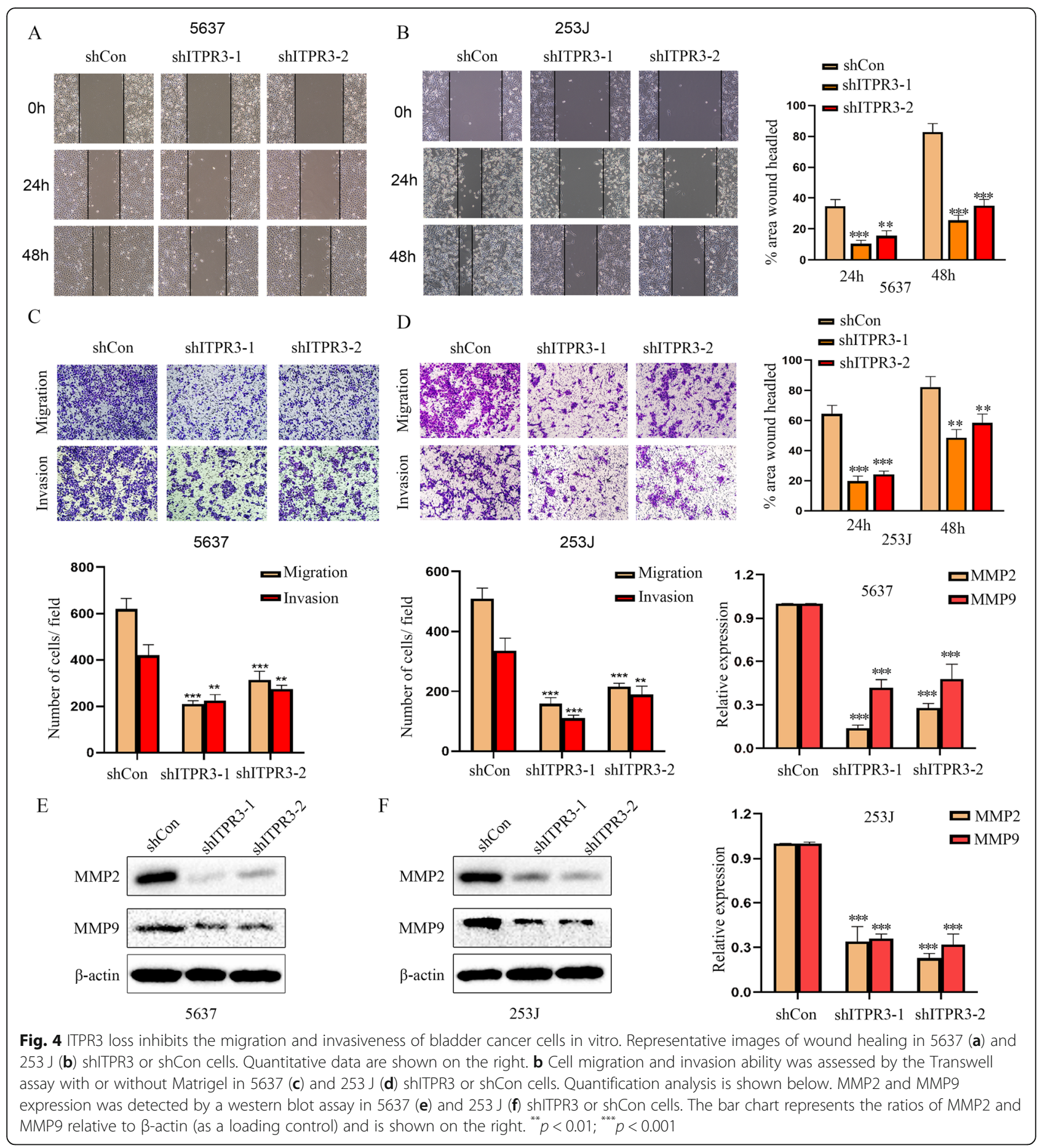

All these data suggested that ITPR3 might act as an important factor in bladder cancer metastasis.

\section{ITPR3 inhibition blocks epithelial-mesenchymal transition} in bladder cancer cells

Epithelial-mesenchymal transformation (EMT) can result in morphological changes from polygonal to spindle-shaped, which makes cells more susceptible to distant metastasis. EMT is also the leading cause of distant metastasis, which can lead to poor prognoses of cancers $[18,19]$. Until now, the potential effect of ITPR3 on EMT has not yet been reported. As shown in Fig. 5a, ITPR3 depletion blocked EMT by simultaneously upregulated an epithelial marker (E-cadherin) and downregulated mesenchymal markers ( $\mathrm{N}$-cadherin, Vimentin, Snail 1, and Snail 2) in 5637 and $253 \mathrm{~J}$ cells. TGF- $\beta$ 


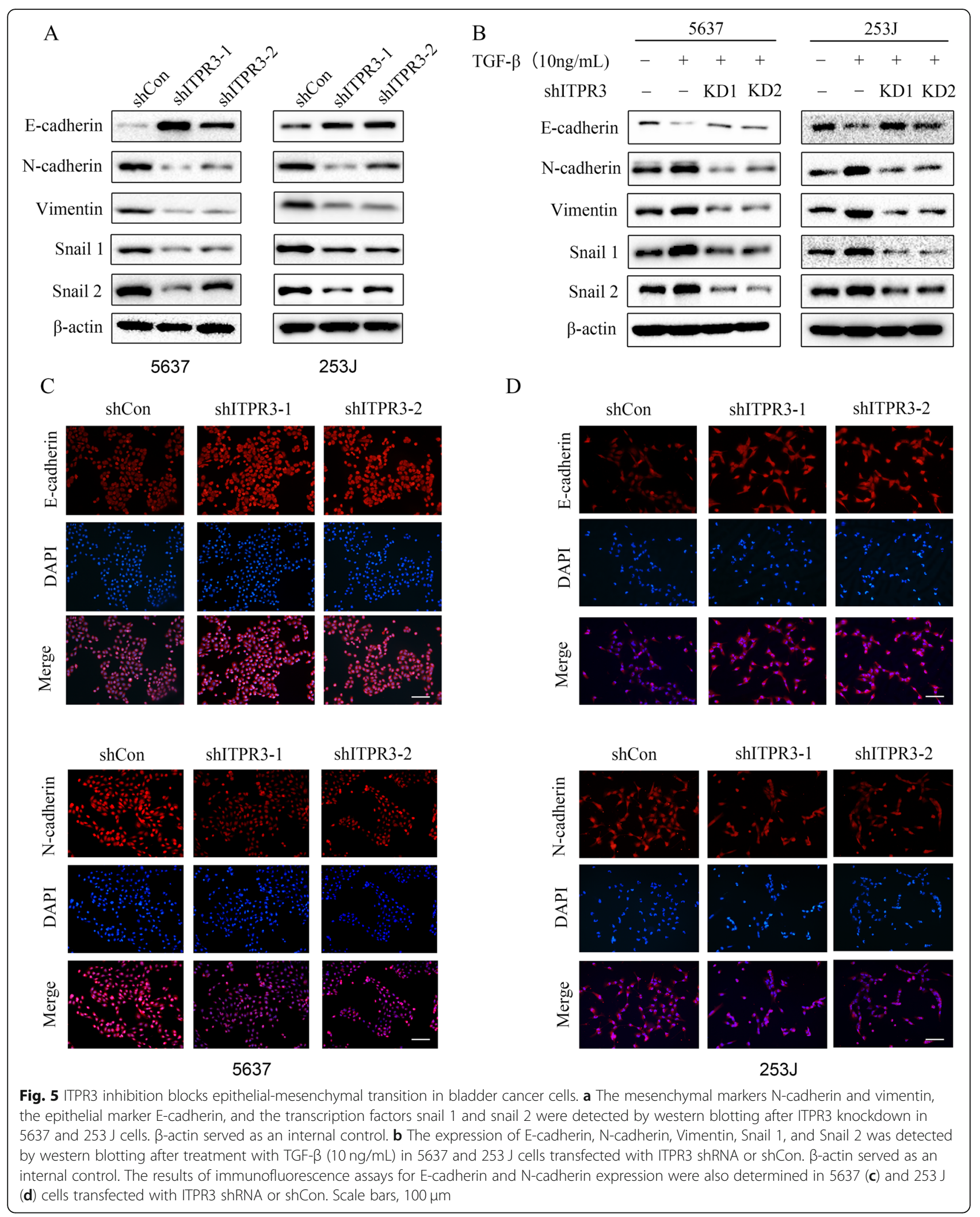


(transforming growth factor- $\beta$ ), acting as a classical activator of EMT, was used to assess the potential role of ITPR3 in EMT. The results revealed that ITPR3 depletion blocked the activation of EMT induced by TGF- $\beta$ (Fig. 5b). Similar results were also observed in the immunofluorescence assay, in which E-cadherin was upregulated and $\mathrm{N}$-cadherin was downregulated in 5637 and $253 \mathrm{~J}$ cells after ITPR3 suppression (Fig. 5c, d). These results suggested that ITPR3 knockdown blocked epithelial-to-mesenchymal transition in bladder cancer cells.

ITPR3 knockdown suppresses the stemness properties of bladder cancer cells

An increasing number of studies have confirmed that cancer stem cells (CSCs) play a vital role in promoting tumor development, relapse, and metastasis and have intrinsic self-renewal characteristics and tumorigenic properties. CSCs might be the root cause of malignant progression and resistance to cancer therapy [20, 21]. Therefore, inhibition of cancer stemness may contribute to the development of clinical strategies and may provide a new direction for the future treatment of cancers [22]. Tumorsphere formation assays and colony formation assays were conducted to evaluate the potential effect of ITPR3 on cancer stemness properties. The results showed that tumorsphere and colony formation abilities were suppressed after ITPR3 knockdown (Fig. 6a-c). Consistently, CSC markers such as CD44, P63, OCT4, SOX2 and KLF4 were also decreased in shITPR3 cells compared with shCon cells (Fig. 6d). These results suggested that ITPR3 inhibition impaired the CSC phenotype in $\mathrm{BCa}$ cells.

\section{ITPR3-mediated NF-KB/CD44 signaling in BCa cells}

$\mathrm{NF}-\kappa \mathrm{B}$ signaling plays a vital role in cancer initiation and progression and is abnormally activated in various cancers [23]. CD44, which is a cell surface glycoprotein and a CSC marker in BCa cells, is involved in various cellular processes, including cell adhesion, migration, and proliferation. However, the relationship and potential interaction between the two molecules in bladder cancer are still unknown. As shown in Fig. 6, we demonstrated that ITPR3 knockdown suppressed cancer stemness by decreasing the CD44 protein level. A similar result was also observed in the immunofluorescence assay for 5637 and 253 J cells (Fig. 7e). As shown in Fig. 7a, ITPR3 knockdown blocked the translocation of NF- $\mathrm{KB}$ (P65) from the cytoplasm to the nucleus induced by TNF $\alpha$ in 5637 and $253 \mathrm{~J}$ cells. Similar results were also observed in the western blot assay (Fig. 7c). Meanwhile, GSEA analysis was conducted and indicated that $41 / 50$ gene sets were upregulated in the ITPR3 high-expression group. Coincidentally, "HALLMARK_TNFA_SIGNALING_VIA_NFKB" was also found to be upregulated when ITPR3 was highly expressed (Fig. 7b). All the results indicated that ITPR3 loss suppressed the nuclear translocation of NF-kB. Western blot analysis also showed that ITPR3 knockdown inactivated the NF- $k B$ signaling pathway by decreasing the expression of $\mathrm{P}$ $\mathrm{IKBa}$ and $\mathrm{P}-\mathrm{NFKB}$ while increasing the expression of $\mathrm{IKBa}$, which is an inhibitory factor of NF-kB (Fig. 7d). Previous studies have found that NF- $\kappa B$ might be upstream in the regulation of the expression of CD44 in other types of cancer [24, 25]. Therefore, we will focus on whether and how the two molecules interact in bladder cancer. To investigate the role of the NF$\kappa \mathrm{B}$ signaling pathway in regulating $\mathrm{CD} 44$ expression in $\mathrm{BCa}$ cells, bladder cancer cells were treated with TNF $\alpha$ (an activator of NF-kB signaling) after ITPR3 knockdown, and we found that TNF $\alpha$ reversed the expression of P-NFKB and CD44 simultaneously suppressed by ITPR3 knockdown, which indicated that activation of the NF- $\mathrm{kB}$ signaling pathway antagonized the low expression of CD44 caused by ITPR3 knockdown and that NF-kB functioned upstream of CD44 in $\mathrm{BCa}$ cells (Fig. 7f). In brief, these results suggested that ITPR3 mediated the NF-KB/CD44 signaling pathway in $\mathrm{BCa}$ cells.

\section{ITPR3 regulates proliferation and stemness via the NF-KB/ CD44 signaling pathway in $\mathrm{BCa}$}

From the results above, we know that ITPR3 can regulate the NF- $\mathrm{kB} / \mathrm{CD} 44$ signaling pathway in BCa. Next, it is necessary to dissect the mechanisms of NF- $\mathrm{kB} / \mathrm{CD} 44$ signaling in regulating the malignant progression of bladder cancer. The key role of CD44 in maintaining the cancer stemness of $\mathrm{BCa}$ cells is inseparable from tumor growth, distant metastasis, and drug resistance. We established stable subcellular lines with ectopic CD44 overexpression in 5637 and $253 \mathrm{~J}$ shITPR3 cells. Here, we hypothesized that increased CD44 expression levels and activation of the NF- $\mathrm{KB}$ signaling pathway may be involved in ITPR3-promoted BCa growth and stemness. As is shown in Fig. 8a, Both TNFa treatment and CD44 overexpression partly reversed the proliferation inhibition induced by ITPR3 knockdown. Similar results were also observed in the EdU assay and colony formation assay (Fig. 8b, c). As expected, TNFo treatment and CD44 overexpression also significantly potentiated the CSC phenotype of BCa cells suppressed by ITPR3 knockdown (Fig. 8d). Consistently, western blotting data clearly showed that specific markers of proliferation and CSCs, such as CD44, SOX2, OCT4, and CDK2, were also upregulated after treatment as described above (Fig. 9e). These results collectively indicated that the oncogenic property of ITPR3 was mediated by the activation of the NF-kB/CD44 signaling pathway. 


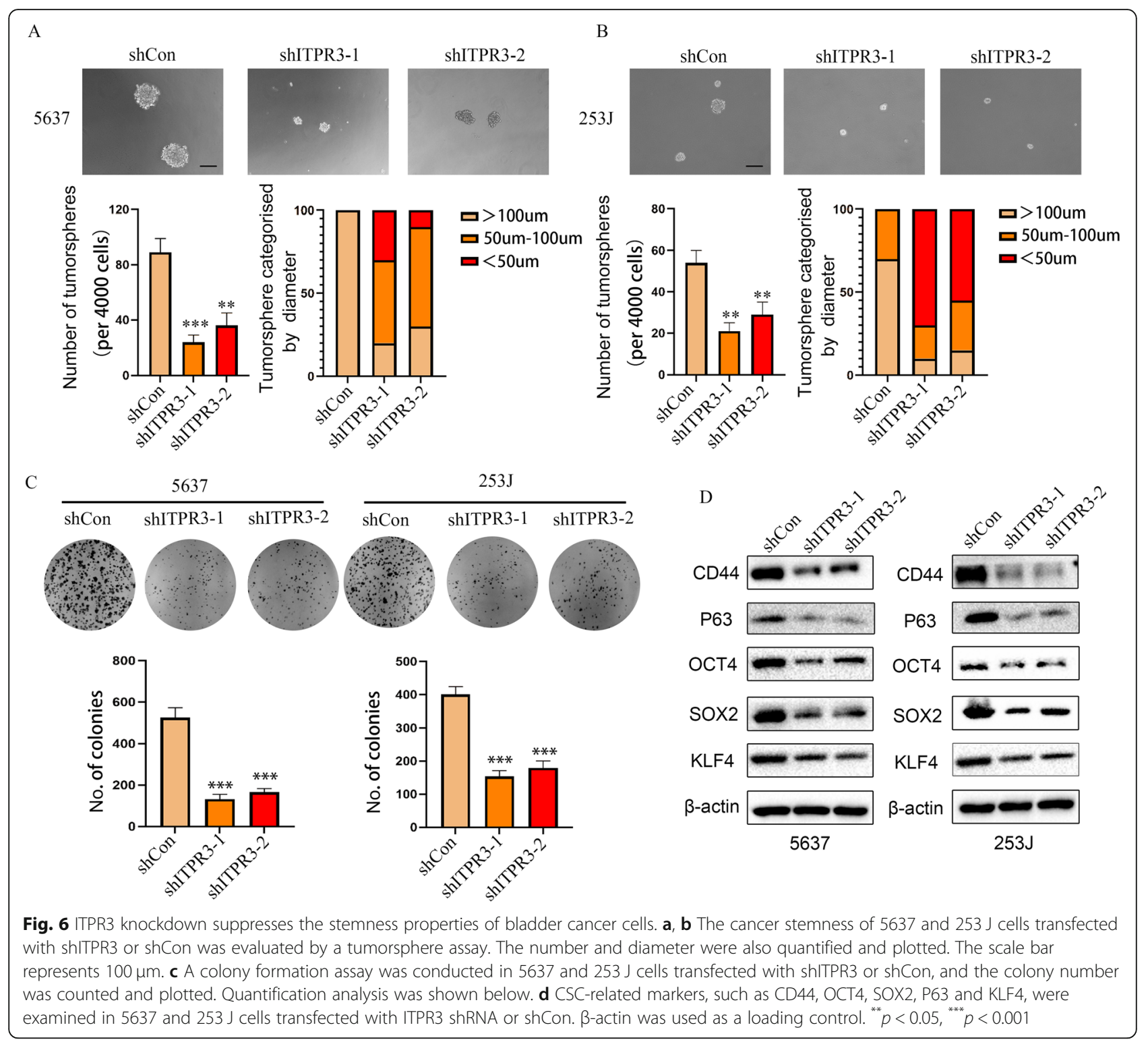

\section{ITPR3 regulates EMT via the NF-KB/CD44 signaling pathway in $\mathrm{BCa}$}

Recent studies have reported that EMT and CSCs always appear coincidently, and EMT has been identified as a critical regulator of the CSC phenotype in tumors [26]. CSCs can accelerate the EMT process, thus leading to distant metastasis [27]. Hence, a greater understanding of the interaction between EMT and CSCs will contribute to improvements in clinical treatment strategies. Transwell assays were conducted to evaluate the migration and invasiveness of 5637 and 253 shITPR3 cells after treatment with TNF $\alpha$ or ectopic CD44 overexpression, and a schematic diagram of the Transwell assay is shown in Fig. 9b. As is shown in Fig. 9a, both TNF $\alpha$ treatment and CD44 overexpression partly reversed the migration and invasiveness inhibition induced by ITPR3 knockdown, and similar results were also observed in the wound healing assay (Fig. 9c). Consistent with the results observed above, western blot assays showed that $\mathrm{N}$-cadherin, vimentin and MMP2 were upregulated while E-cadherin was downregulated in 5637 and 253 J shITPR3 cells after TNF $\alpha$ and ectopic CD44 overexpression treatment (Fig. 9d). These results indicated that ITPR3 regulated EMT via the NF-kB/CD44 signaling pathway in BCa cells.

\section{ITPR3 knockdown attenuated the tumorigenicity of $\mathrm{BCa}$ in vivo}

The tumorigenicity of ITPR3 in vivo was validated in a xenograft model. We injected ITPR3-depleted or control 5637 cells into nude mice. Tumor volumes and body weights were measured every three days within 30 days, 


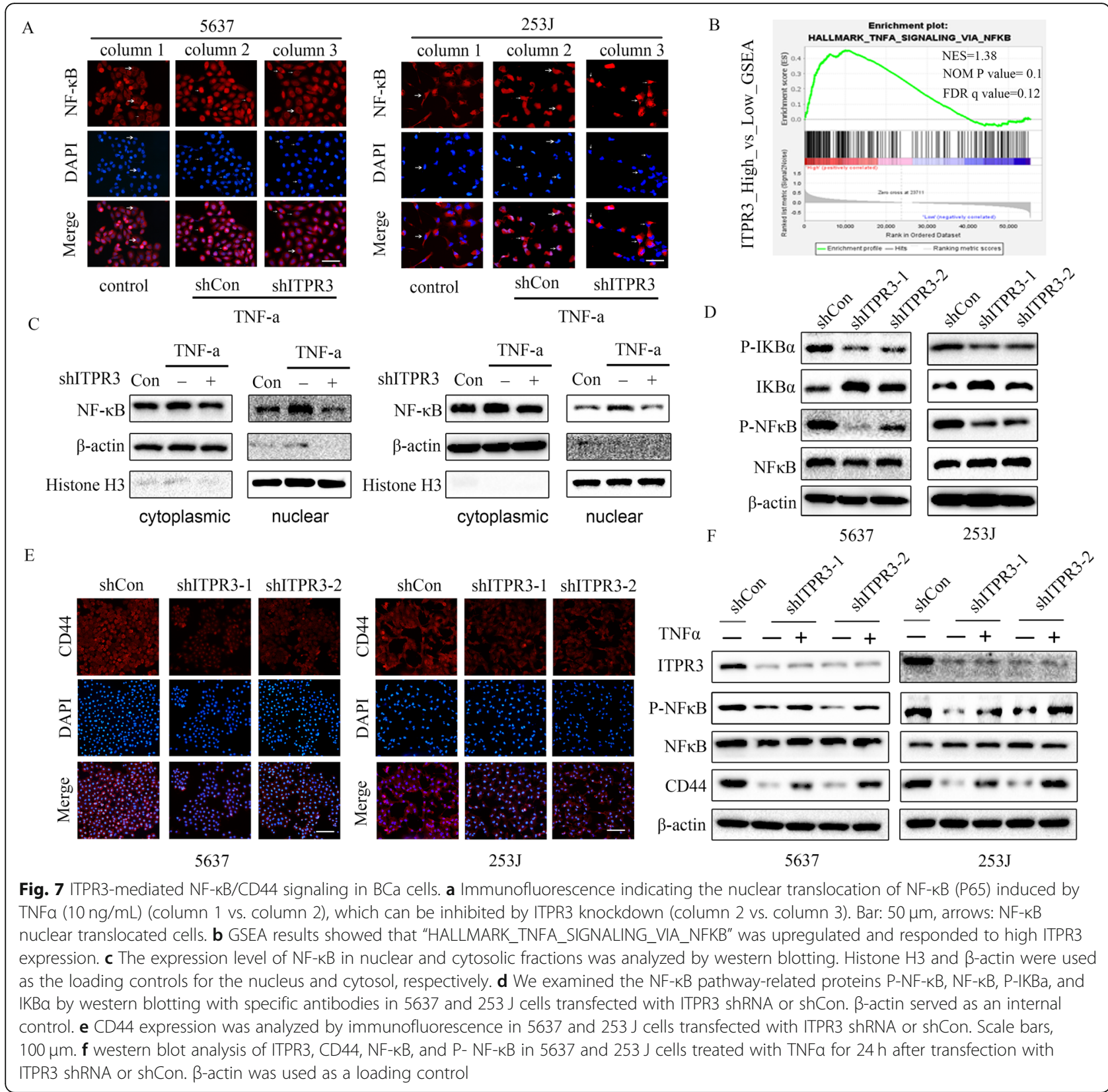

and tumors were harvested after the mice were sacrificed (Fig. 10a). Representative images of tumors are presented in Fig. 10b. As shown in Fig. 10c, the xenograft tumors grew more slowly after ITPR3 knockdown compared with the control, and the tumor weight was much lighter in the ITPR3-depleted group. Western blot assays were also conducted to detect the expression of related genes. The results showed that ITPR3, P-NF-kB, CD44, and Ki-67 were downregulated, while IKBa was upregulated after ITPR3 knockdown (Fig. 10d). Moreover, immunohistochemistry staining showed that ITPR3, CD44 and Ki-67 were weaker, while IKBa was stronger in ITPR3-silenced tumor tissues (Fig. 10e). These results suggested that ITPR3 knockdown attenuated the tumorigenicity of $\mathrm{BCa}$ in vivo.

ITPR3 knockdown suppressed BCa cell distant metastasis in vivo

The T24-L subcell line tagged with luciferase was used to establish the tail vein injection metastasis model, which was used to evaluate the potential role of ITPR3 in $\mathrm{BCa}$ distant metastasis. A schematic diagram of the experimental procedure is shown in Fig. 11a, which was also described in our previous study [12]. Bioluminescence imaging (BLI) showed that lung metastasis was almost abolished after ITPR3 knockdown compared with 


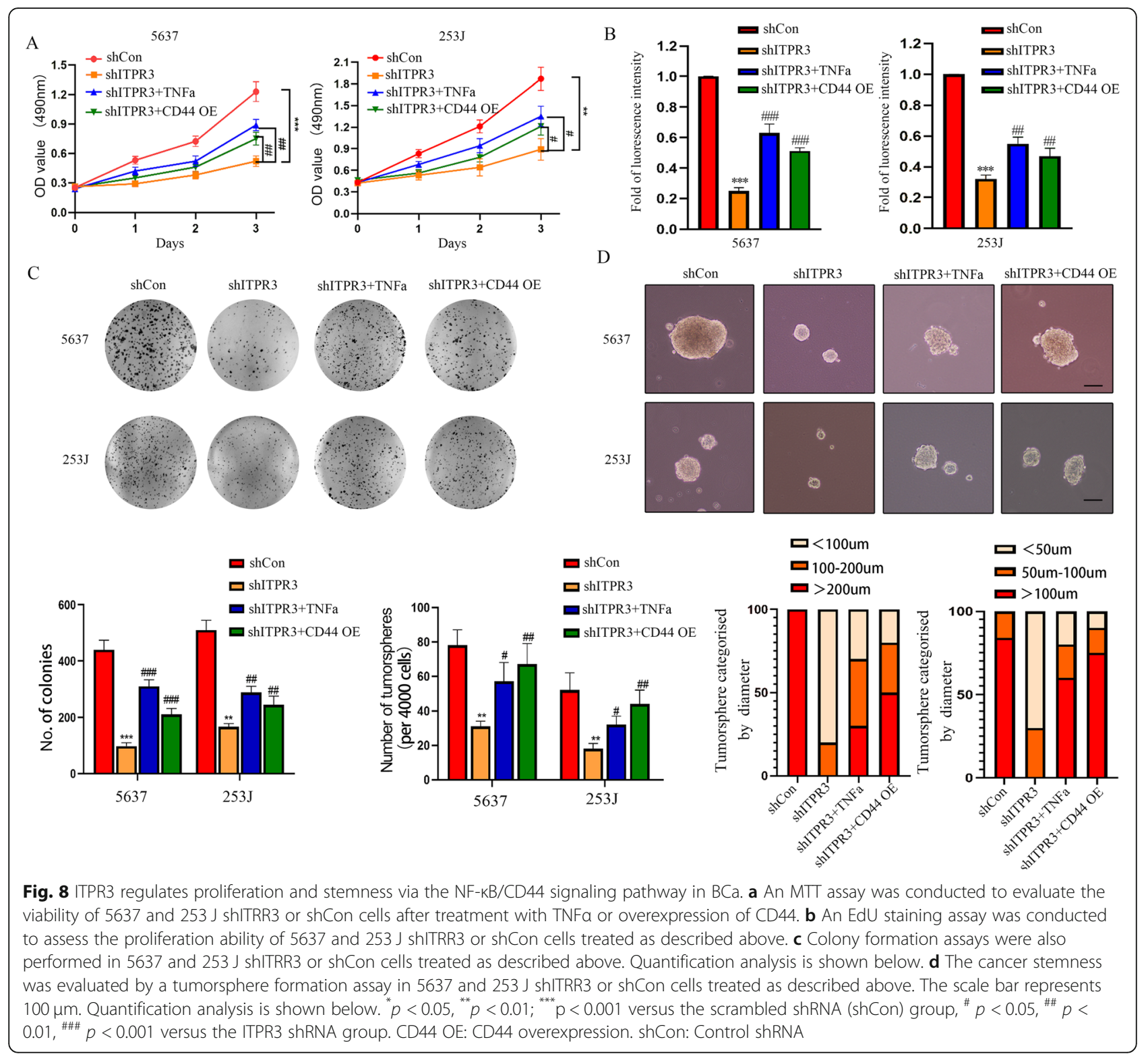

the control (Fig. 11b). Similar results were also observed by hematoxylin-eosin staining, in which the formation of lung metastatic foci was significantly suppressed in shITPR3 T24-L cells compared with control shRNA cells (Fig. 11c). Lungs were removed to observe the number of lung surface metastatic foci, and ITPR3 depletion obviously reduced the metastatic nodules in mouse lungs compared with the control (Fig. 11d, e). Meanwhile, there was no distinct change in body weight between the shITPR3 T24-L cells and shCon T24-L cells (Fig. 11f). IHC (immunohistochemistry) also showed that ITPR3, CD44, and N-cadherin were weaker, while IKBa and Ecadherin were stronger in the ITPR3-depletion group (Fig. 11g). These results indicated that ITPR3 knockdown inhibited BCa metastasis in vivo.

\section{Discussion}

Patients with metastatic BCa usually suffer a poor prognosis due to a lack of an effective treatment strategy [28]. In $\mathrm{BCa}$, distant metastasis, especially lung metastasis, and chemoresistance are the two leading causes of death. Therefore, there is an urgent need to explore more molecular mechanisms of $\mathrm{BCa}$ malignant progression.

ITPRs are ubiquitous $\mathrm{Ca} 2+$ channels located at mitochondria/endoplasmic reticulum (ER) contact sites and can interact with GRP75 to accelerate the transmission of calcium from the lumen of the ER directly into mitochondria [29]. Intracellular calcium $(\mathrm{Ca} 2+)$ signaling pathways mediate various cellular processes, including tumor development and proliferation, gene transcription, 


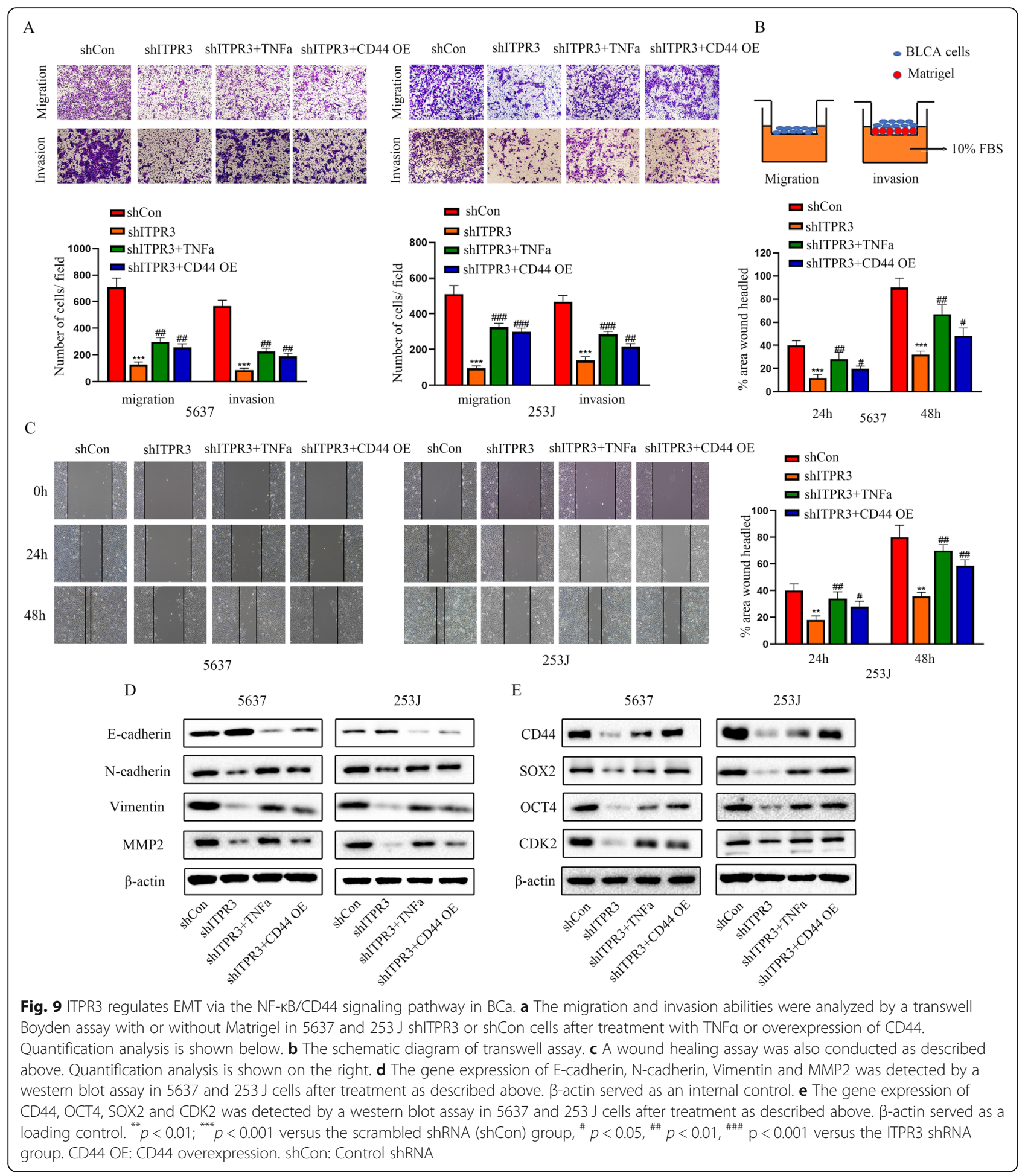

cell migration and invasion, cell apoptosis and necrosis [7]. ITPR 3 accounts for $90 \%$ of ITPRs, while ITPR 1 and ITPR 2 constitute approximately $10 \%$ [30]. Previous studies have failed to address the specific mechanism of ITPR3 oncogenic roles in a variety of cancers, which attracts our attention. Several investigators have reported that the loss of ITPR3 can impair mitochondrial calcium signaling and reduce apoptosis, thus leading to premalignant conditions in various cancers, such as melanoma and mesothelioma [31]. While in prostate cancer, ITPR3 can limit tumor growth by regulating $\mathrm{Ca} 2+-$ dependent apoptosis, in which the more ITPR3 is degraded, the less 


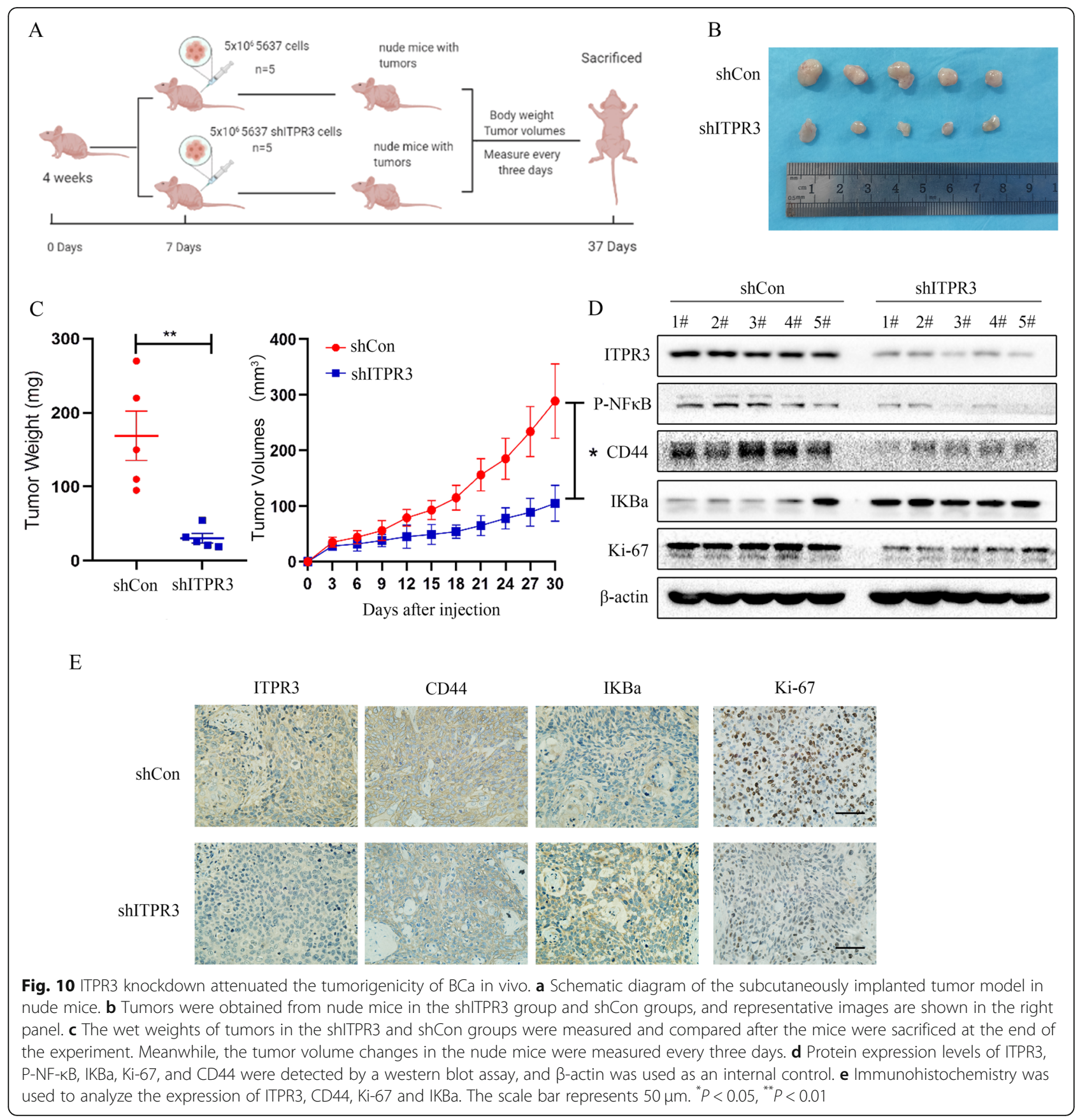

apoptosis occurs [32]. In colon cancer, increased ITPR3 expression is related to increased metastasis and decreased patient survival, and increased ITPR3 can lead to reduced apoptosis or vice versa [33]. A similar phenomenon was also observed in hepatocellular carcinoma and cholangiocarcinoma $[7,9]$. It is worth noting that we demonstrated for the first time that ITPR3 was overexpressed and served as an oncogene in bladder cancer. Previous studies have confirmed that ITPR3 can be suppressed by transcription factors or miRNAs [34, 35], while the factors causing the overexpression of
ITPR3 are not yet clear. Methylation is an important modification of protein and nucleic acid, which can regulate gene expression and shutdown. Meanwhile, Methylation is closely related to cancer, aging, Alzheimer's disease, and many other diseases, and is also one of the important contents of epigenetics research [36]. Gene methylation is closely related to gene expression level and the stability of chromatin. In general, activation of proto-oncogenes is accompanied by demethylation of their promoters and demethylation of DNA is a rapid, independent, and distinct process from cell division. 


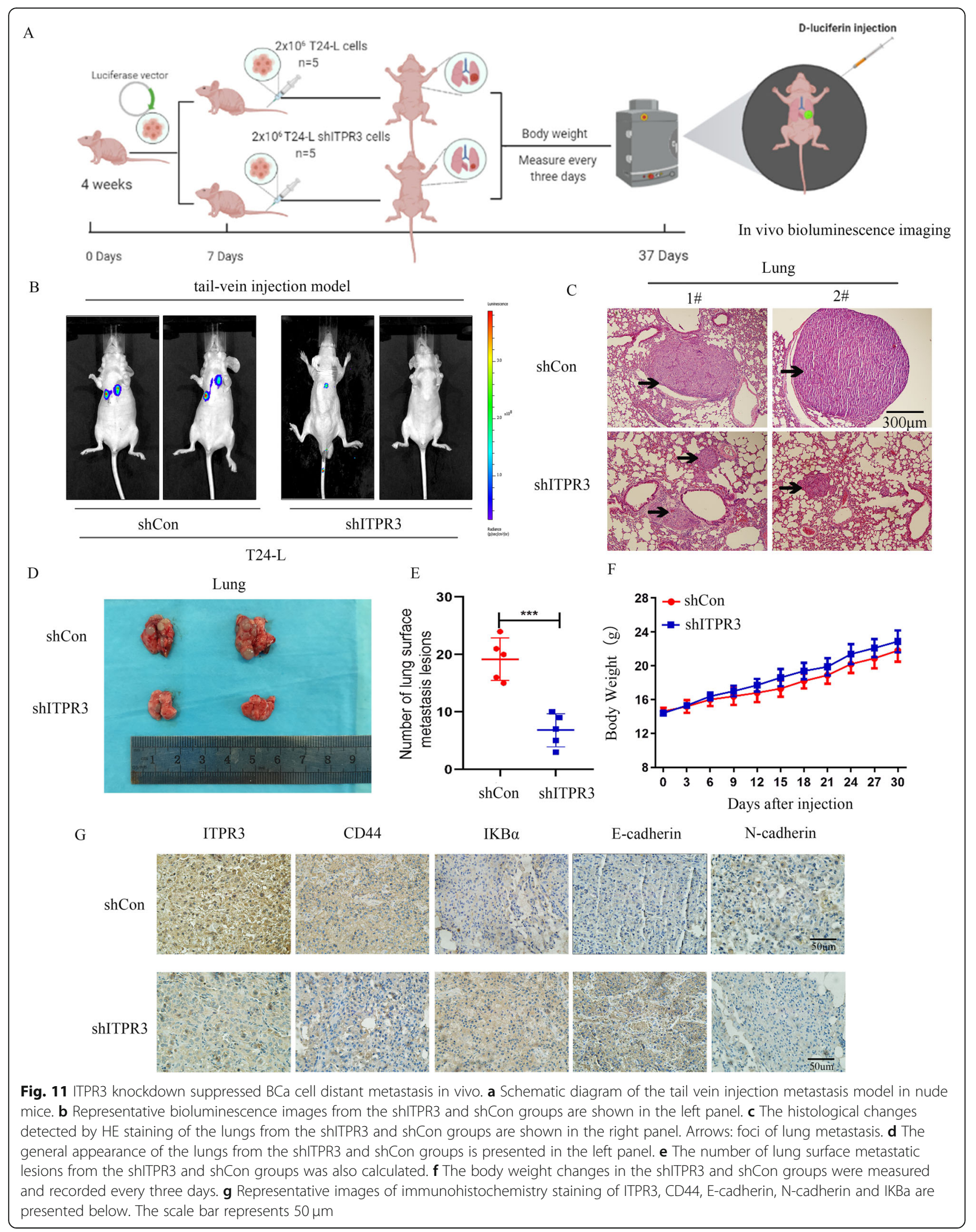


Both hypermethylation of tumor suppressor genes as well as hypomethylation of oncogenes genes are characteristic of cancer cells. As DNA methylation is reversible, Demethylation may play an important role in the occurrence and development of tumors [37]. Bioinformatic analysis has confirmed that there are four CpG islands in the ITPR3 promoter region, including three $\mathrm{CpG}$ islands longer than $200 \mathrm{bp}$. BSP also confirmed that the methylation of the ITPR3 promoter in the normal bladder cell line SVHUC-1 was higher than that in the bladder cancer cell lines (5637 and $253 \mathrm{~J}$ ) at 43 different CpG sites in 10 clones, and there was also a negative correlation between the mRNA level and methylation level in ITPR3 in bladder cancer. 5-Aza, as a DNA methyltransferase inhibitor, can also upregulate the expression of ITPR3 in SVHUC-1 cells, which indicates that the expression of ITPR3 could be affected by the methylation level in the gene promoter. Therefore, we can conclude that demethylation of the ITPR3 promoter is responsible for its high expression in bladder cancer. From our work in this research, we demonstrated the oncogenic role of ITPR3 in bladder cancer in contrast to the roles of ITPR1 and ITPR2, whose proapoptotic effect was already described [6]. We also found that ITPR1 was expressed at low levels in bladder cancer, while there was no obvious difference in ITPR2 expression compared with normal expression which was consistent with the result of western-blot. Considering the contradictory roles of ITPR1, ITPR2 and ITPR3 in tumors, a western blot assay was conducted to assess the expression of ITPR1 and ITPR2 when ITPR3 was knocked down. The results showed that ITPR3 depletion upregulated the expression of ITPR1 but had no effect on ITPR2 (Supplementary Fig. 2). What is the mechanism by which ITPR3 realizes its oncogenic effect? From the results above, we hypothesize that the oncogenic effect of ITPR3 is partly attributed to the inhibition of ITPR 1 and that the ratio of ITPR3/ITPR1 may determine the destiny of cancer cells which is consistent with the conjectures in the previous research [6].

It is generally accepted that CSCs (cancer stem cells) are defined as a subpopulation of highly tumorigenic cancer cells with self-renewal activity, and they have been reported to exist in various types of cancer [38]. Cancer stem cells (CSCs) mediate tumor initiation and maintenance, which can contribute to distant metastasis and a poor prognosis. EMT was reported to exist in the cancer stem cell population and is driven by CSCs [39]. Therefore, CSC-targeting therapy has already become a new direction for the treatment of cancer in the future, especially metastatic cancer. As shown in Supplementary Fig. 3, ITPR3 and CSC markers such as CD44, SOX2 and OCT4 were enriched in BCa stem cells, which

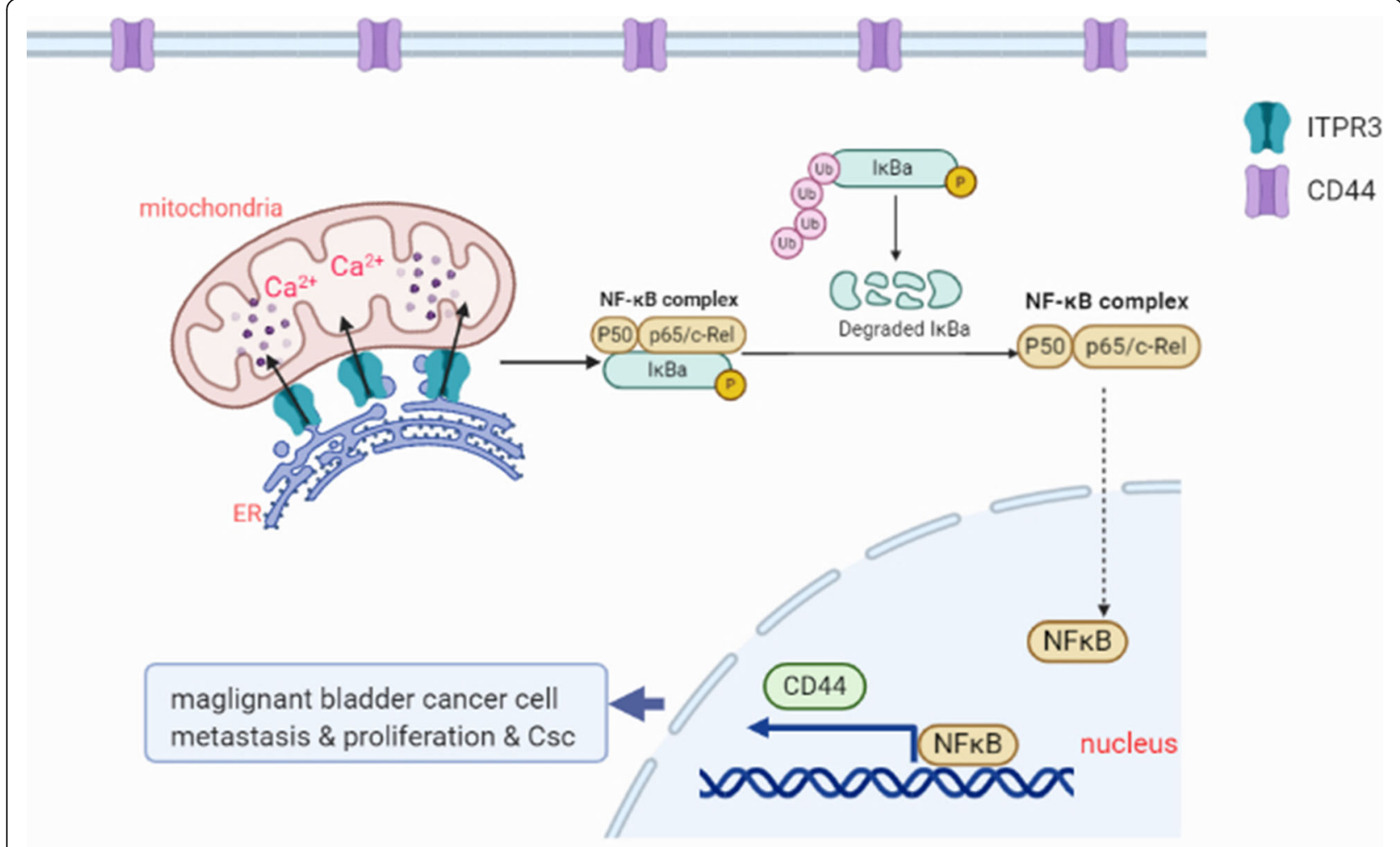

Fig. 12 An illustration of how ITPR3 facilitates tumor growth, metastasis and stemness by inducing the NF-KB/CD44 pathway 
indicated that ITPR3 might play a vital role in maintaining the cancer stemness phenotype. We demonstrated that ITPR3 depletion suppressed cancer cell proliferation, migration, invasion and stemness by inhibiting the expression of CD44, which is the main cancer stem cell marker in bladder cancer [40].

NF- $\mathrm{kB}$ (nuclear factor (NF)-kappa B) serves as a transcription factor and has been reported to activate various genes, including inflammatory cytokines and oncogenes, which suppress the apoptosis of cancer cells. NF- $k B$ is usually abnormally activated in cancers and plays a vital role in promoting cancer development and progression, in addition to hindering the effectiveness of chemo- and radiation therapies [41]. In this research, GSEA was used to verify that "HALLMARK_TNFA_SIGNALING_VIA_ NFKB" was upregulated when ITPR3 was highly expressed. The heat map and other gene sets are also shown in Supplementary Fig. 4. ITPR3, as an oncogene, plays a critical role in promoting proliferation and metastasis and maintaining tumor stemness depending on NF$\kappa B$ activation. Meanwhile, CD44 expression was suppressed by the inactivation of NF- $\mathrm{kB}$ signaling induced by ITPR3 knockdown. Nevertheless, how ITPR3 influence $\mathrm{Ca}+$ signaling and the relationship between the $\mathrm{Ca}+$ signaling and NF- $\mathrm{KB}$ signaling should be further analyzed.

\section{Conclusion}

In conclusion, we demonstrated in this research that ITPR3, as an oncogenic gene, promoted the proliferation, metastasis and stemness of bladder cancer through the NF- $\mathrm{KB} / \mathrm{CD} 44$ signaling pathway. CD44, as a stem cell marker of bladder cancer could be regulated by NF- $\mathrm{KB}$ signaling pathway which played an important role in bladder cancer. Taken together, ITPR3 could be a novel prognostic marker and drug target for $\mathrm{BCa}$, especially metastatic BCa (Fig. 12).

\section{Supplementary Information}

The online version contains supplementary material available at https://doi. org/10.1186/s13046-021-01866-1

Additional file 1: Supplementary Figure 1. Bioinformatics analysis of ITPR3 expression in bladder cancer and correlation between ITPR3 and overall survival in BCa patients. (A) ITPR3 mRNA expression in bladder cancer tissue and normal adjacent tissue from the GEPIA website based on TCGA database. (B, C) ITPR3 mRNA expression in bladder cancer tissues and adjacent tissues from the TCGA dataset and GEO (GSE3167, GDS183) dataset. (D) ITPR3 is significantly upregulated in bladder cancer (left), as is ITPR3 mRNA expression in multiple kinds of cancers (right), which was analyzed from the Oncomine database. (E) ITPR3 was overexpressed in bladder cancer compared with normal tissues in Sanchez-Carbayo's research from the Oncomine dataset. (F) Kaplan-Meier analysis of overall survival (OS) and disease-free survival (DFS) in BCa patients with high $(n=201)$ and low $(n=201)$ ITPR3 mRNA expression from TCGA database.

Additional file 2: Supplementary Figure 2. The expression of ITPRs in $\mathrm{BCa}$ and the relationship between ITPR3 and ITPR1 or ITPR2. (A) Analysis of ITPR1, ITPR2, and ITPR3 mRNA expression in bladder cancer and normal tissues from the TCGA dataset. (B) ITPR1, ITPR2, and ITPR3 mRNA expression levels in SV-HUC-1, 5637, and $253 \mathrm{~J}$ cells were detected by a qRT-PCR assay. (C) ITPR1, ITPR2, and ITPR3 protein levels were examined by a western blot assay in 5637 cells transfected with shITPR3 or shCon.

Additional file 3: Supplementary Figure 3. ITPR3 was enriched in the CSC. (A) The morphological differences of 5637 and CSCs derived from 5637 cells were captured by contrast microscopy. (B) $253 \mathrm{~J}$ was also observed in the same way. (C) The expression of ITPR3 and cancer stem cell markers such as CD44, SOX2, and OCT4 was detected by western blot assay in 5637 and CSCs derived from 5637 cells. (D) The expression of ITPR3 and cancer stem cell markers such as CD44, SOX2, and OCT4 was detected by a western blot assay in $253 \mathrm{~J}$ and CSCs derived from $253 \mathrm{~J}$ cells

Additional file 4: Supplementary Figure 4. GSEA analysis of ITPR3 in the TCGA dataset and significantly changed cell signaling pathways in 50 hallmark gene sets by ITPR3 expression. (A) Heat map of the top 100 genes upregulated or repressed in the ITPR3 high-expression and ITPR3 low-expression BCa patient groups. (B) The significantly changed cell signaling pathways in 50 hallmark gene sets from GSEA analysis of ITPR3 expression in the BCa TCGA dataset.

\section{Abbreviations}

BCa: Bladder cancer; CSC: Cancer stem cell; NF-kB: Nuclear factor-kappaB; IKBa: NF-kappa-B inhibitor alpha; ITPR3: Inositol 1,4,5-Trisphosphate Receptor type 3; EMT: Epithelial-mesenchymal transition; TGF- $\beta$ : Transforming growth factor- $\beta$; TNFa: Tumor necrosis factor a; MTT: 3-(4,5-dimethylthiazol-2-yl)-2,5diphenyl tetrazolium bromide; 5-Aza: 5-Aza-2'-deoxycytidine;

HE: Hematoxylin-eosin; DMEM: Dulbecco's modified Eagle medium; FBS: Fetal bovine serum; BSP: Bisulfite sequencing PCR; T24-L: T24-T-Luciferase-Lung subcell line; NMIBC: Non-muscle invasive bladder cancer; MIBC: Muscle invasive bladder cancer

\section{Acknowledgments}

We acknowledge and appreciate our colleagues for their valuable efforts and comments on this paper.

\section{Authors' contributions}

M.Z. Z, L. W, and L. Z performed the experiments. T.J. L, M.X. J, and Y.Y. Y analyzed and interpreted the data. J.H. F and M.Z. Z wrote the manuscript. X. $L$ and M.H. M provided critical suggestions. S. X, K. W and X.Y. W revised the manuscript critically for important intellectual content. J.H. F designed and supervised the project. All authors discussed the results and commented on the manuscript. The authors read and approved the final manuscript.

\section{Funding}

This work was supported by the National Natural Science Foundation of China (No: 81572520).

\section{Availability of data and materials}

The datasets generated/analyzed during the current study are available.

\section{Ethics approval and consent to participate}

This study was approved and supervised by the Ethical Committee of the First Affiliated Hospital of Medical College, Xi'an Jiaotong University, Xi'an, China. The study was conducted in accordance with the Declaration of Helsinki principles.

\section{Consent for publication}

The manuscript has been approved by all authors for publication.

\section{Competing interests}

The authors have no conflicts of interest to declare.

\section{Author details}

'Department of Urology, The First Affiliated Hospital of Xi'an Jiaotong University, \#277 Yanta West Road, Xi'an 710061, China. ${ }^{2}$ Department of Hepatobiliary Surgery, First Affiliated Hospital of Xi'an Jiaotong University, Xi'an, China. ${ }^{3}$ Oncology Research Lab, Key Laboratory of Environment and Genes Related to Diseases, Ministry of education, Xi'an, China. 
Received: 20 December 2020 Accepted: 2 February 2021

Published online: 11 February 2021

\section{References}

1. Klotz L, Brausi MA. World urologic oncology federation bladder Cancer prevention program: a global initiative. Urol Oncol. 2015;33(1):25-9.

2. Witjes JA, Comperat E, Cowan NC, De Santis M, Gakis G, Lebret T, et al. EAU guidelines on muscle-invasive and metastatic bladder cancer: summary of the 2013 guidelines. Eur Urol. 2014;65(4):778-92.

3. Siegel RL, Miller KD, Jemal A. Cancer statistics, 2019. CA Cancer J Clin. 2019; 69(1):7-34.

4. Alfred Witjes J, Lebret T, Comperat EM, Cowan NC, De Santis M, Bruins HM, et al. Updated 2016 EAU guidelines on muscle-invasive and metastatic bladder Cancer. Eur Urol. 2017;71(3):462-75.

5. Mangla A, Guerra MT, Nathanson MH. Type 3 inositol 1,4,5-trisphosphate receptor: a calcium channel for all seasons. Cell Calcium. 2020;85:102132.

6. Rezuchova I, Hudecova S, Soltysova A, Matuskova M, Durinikova E, Chovancova B, et al. Type 3 inositol 1,4,5-trisphosphate receptor has antiapoptotic and proliferative role in cancer cells. Cell Death Dis. 2019;10(3):186.

7. Ueasilamongkol P, Khamphaya T, Guerra MT, Rodrigues MA, Gomes DA, Kong $Y$, et al. Type 3 inositol 1,4,5-Trisphosphate receptor is increased and enhances malignant properties in Cholangiocarcinoma. Hepatology. 2020; 71(2):583-99.

8. Sneyers F, Rosa N, Bultynck G. Type 3 IP3 receptors driving oncogenesis. Cell Calcium. 2020;86:102141.

9. Guerra MT, Florentino RM, Franca A, Lima Filho AC, Dos Santos ML, Fonseca $\mathrm{RC}$, et al. Expression of the type 3 InsP3 receptor is a final common event in the development of hepatocellular carcinoma. Gut. 2019;68(9):1676-87.

10. Wu K, Ning Z, Zeng J, Fan J, Zhou J, Zhang T, et al. Silibinin inhibits betacatenin/ZEB1 signaling and suppresses bladder cancer metastasis via dualblocking epithelial-mesenchymal transition and stemness. Cell Signal. 2013; 25(12):2625-33.

11. Zhang M, Du H, Huang Z, Zhang P, Yue Y, Wang W, et al. Thymoquinone induces apoptosis in bladder cancer cell via endoplasmic reticulum stressdependent mitochondrial pathway. Chem Biol Interact. 2018;292:65-75.

12. Zhang $M$, Du H, Wang L, Yue $Y$, Zhang $P$, Huang $Z$, et al. Thymoquinone suppresses invasion and metastasis in bladder cancer cells by reversing EMT through the Wnt/beta-catenin signaling pathway. Chem Biol Interact. 2020; 320:109022.

13. Subramanian A, Tamayo P, Mootha VK, Mukherjee S, Ebert BL, Gillette MA, et al. Gene set enrichment analysis: a knowledge-based approach for interpreting genome-wide expression profiles. Proc Natl Acad Sci U S A. 2005;102(43):15545-50.

14. Hanahan D, Weinberg RA. Hallmarks of cancer: the next generation. Cell. 2011;144(5):646-74.

15. Yue Y, Hui K, Wu S, Zhang M, Que T, Gu Y, et al. MUC15 inhibits cancer metastasis via PI3K/AKT signaling in renal cell carcinoma. Cell Death Dis. 2020;11(5):336

16. Kessenbrock K, Plaks V, Werb Z. Matrix metalloproteinases: regulators of the tumor microenvironment. Cell. 2010;141(1):52-67.

17. Javadian M, Gharibi T, Shekari N, Abdollahpour-Alitappeh M, Mohammadi A, Hossieni $A$, et al. The role of microRNAs regulating the expression of matrix metalloproteinases (MMPs) in breast cancer development, progression, and metastasis. J Cell Physiol. 2019;234(5):5399-412.

18. Dongre A, Weinberg RA. New insights into the mechanisms of epithelialmesenchymal transition and implications for cancer. Nat Rev Mol Cell Biol. 2019;20(2):69-84.

19. Nieto MA, Huang RY, Jackson RA, Thiery JP. Emt: 2016. Cell. 2016;166(1):21-45.

20. Lytle NK, Barber AG, Reya T. Stem cell fate in cancer growth, progression and therapy resistance. Nat Rev Cancer. 2018;18(11):669-80.

21. Clara JA, Monge C, Yang Y, Takebe N. Targeting signalling pathways and the immune microenvironment of cancer stem cells - a clinical update. Nat Rev Clin Oncol. 2020;17(4):204-32.

22. Zeuner A, Todaro M, Stassi G, De Maria R. Colorectal cancer stem cells: from the crypt to the clinic. Cell Stem Cell. 2014;15(6):692-705.

23. Karin M. Nuclear factor-kappaB in cancer development and progression. Nature. 2006;441(7092):431-6.

24. Smith SM, Lyu YL, Cai L. NF-kappaB affects proliferation and invasiveness of breast cancer cells by regulating CD44 expression. PLoS One. 2014;9(9): e106966.
25. Haria D, Trinh BQ, Ko SY, Barengo N, Liu J, Naora H. The homeoprotein DLX4 stimulates NF-kappaB activation and CD44-mediated tumor-mesothelial cell interactions in ovarian cancer. Am J Pathol. 2015;185(8):2298-308.

26. Shibue T, Weinberg RA. EMT, CSCS, and drug resistance: the mechanistic link and clinical implications. Nat Rev Clin Oncol. 2017;14(10):611-29.

27. Kotiyal S, Bhattacharya S. Breast cancer stem cells, EMT and therapeutic targets. Biochem Biophys Res Commun. 2014;453(1):112-6.

28. Hui K, Gao Y, Huang J, Xu S, Wang B, Zeng J, et al. RASAL2, a RAS GTPaseactivating protein, inhibits stemness and epithelial-mesenchymal transition via MAPK/SOX2 pathway in bladder cancer. Cell Death Dis. 2017;8(2):e2600.

29. Szabadkai G, Bianchi K, Varnai P, De Stefani D, Wieckowski MR, Cavagna D, et al. Chaperone-mediated coupling of endoplasmic reticulum and mitochondrial Ca2+ channels. J Cell Biol. 2006;175(6):901-11.

30. Hirata K, Dufour JF, Shibao K, Knickelbein R, O'Neill AF, Bode HP, et al. Regulation of $\mathrm{Ca}(2+)$ signaling in rat bile duct epithelia by inositol 1,4,5trisphosphate receptor isoforms. Hepatology. 2002;36(2):284-96.

31. Franca A, Carlos Melo Lima Filho A, Guerra MT, Weerachayaphorn J, Loiola Dos Santos M, Njei B, et al. Effects of endotoxin on type 3 inositol 1,4,5-Trisphosphate receptor in human Cholangiocytes. Hepatology. 2019;69(2):817-30.

32. Kuchay S, Giorgi C, Simoneschi D, Pagan J, Missiroli S, Saraf A, et al. PTEN counteracts FBXL2 to promote IP3R3- and Ca (2+)-mediated apoptosis limiting tumour growth. Nature. 2017;546(7659):554-8.

33. Shibao K, Fiedler MJ, Nagata J, Minagawa N, Hirata K, Nakayama Y, et al. The type III inositol 1,4,5-trisphosphate receptor is associated with aggressiveness of colorectal carcinoma. Cell Calcium. 2010;48(6):315-23.

34. Ananthanarayanan M, Banales JM, Guerra MT, Spirli C, Munoz-Garrido P, Mitchell-Richards K, et al. Post-translational regulation of the type III inositol 1,4,5-trisphosphate receptor by miRNA-506. J Biol Chem. 2015;290(1):184-96.

35. Weerachayaphorn J, Amaya MJ, Spirli C, Chansela P, Mitchell-Richards KA, Ananthanarayanan $\mathrm{M}$, et al. Nuclear factor, Erythroid 2-like 2 regulates expression of type 3 inositol 1,4,5-Trisphosphate receptor and calcium signaling in Cholangiocytes. Gastroenterology. 2015;149(1):211-22 e210.

36. Yamashita K, Hosoda K, Nishizawa N, Katoh H, Watanabe M. Epigenetic biomarkers of promoter DNA methylation in the new era of cancer treatment. Cancer Sci. 2018;109(12):3695-706.

37. Cheishvili D, Boureau L, Szyf M. DNA demethylation and invasive cancer: implications for therapeutics. Br J Pharmacol. 2015;172(11):2705-15.

38. Mashima T. Cancer stem cells (CSCs) as a rational therapeutic Cancer target, and screening for CSC-targeting drugs. Yakugaku Zasshi. 2017;137(2):129-32.

39. Tanabe S, Quader S, Cabral H, Ono R. Interplay of EMT and CSC in Cancer and the potential therapeutic strategies. Front Pharmacol. 2020;11:904.

40. Hu Y, Zhang Y, Gao J, Lian X, Wang Y. The clinicopathological and prognostic value of CD44 expression in bladder cancer: a study based on meta-analysis and TCGA data. Bioengineered. 2020;11(1):572-81.

41. Tong $L$, Yuan $Y$, Wu S. Therapeutic microRNAs targeting the NF-kappa $B$ signaling circuits of cancers. Adv Drug Deliv Rev. 2015;81:1-15.

\section{Publisher's Note}

Springer Nature remains neutral with regard to jurisdictional claims in published maps and institutional affiliations.

Ready to submit your research? Choose BMC and benefit from:

- fast, convenient online submission

- thorough peer review by experienced researchers in your field

- rapid publication on acceptance

- support for research data, including large and complex data types

- gold Open Access which fosters wider collaboration and increased citations

- maximum visibility for your research: over $100 \mathrm{M}$ website views per year

At $\mathrm{BMC}$, research is always in progress.

Learn more biomedcentral.com/submissions 